\title{
Las comisiones de investigación en el ámbito municipal
}

\author{
Estrella Fernández Díez \\ Subdirectora General de Asistencia Institucional \\ Secretaría General del Pleno \\ Ayuntamiento de Madrid \\ fernandezde@madrid.es
}

\begin{abstract}
Resumen
En los últimos años, al tiempo que se han ido consolidando las instituciones democráticas, hemos podido asistir al fenómeno de la creación de comisiones de investigación por parte de los ayuntamientos, en clara imitación del uso que de tales instrumentos se hace tanto por las Cortes Generales como por las asambleas legislativas de las diferentes comunidades autónomas.

La falta de regulación expresa de las comisiones de investigación en la normativa sobre régimen local y su escaso desarrollo en aquellos reglamentos orgánicos municipales que las han recogido, aboca a que su análisis pase por el estudio de esos órganos en el seno de los de naturaleza parlamentaria, estatales -Congreso y Senado-y autonómicos, y a su necesaria contextualización en el régimen municipal.
\end{abstract}

Palabras clave

Municipios, comisiones de investigación, instrumentos de investigación, comparecencias, dictamen, conclusiones.

\section{The commissions of inquiry at municipal level}

\begin{abstract}
During the last few years, while democratic institutions have consolidated, we have been able to witness the creation of commissions of inquiry by the municipalities, in clear imitation of the use that the Parliament, as well as the legislative assemblies from the different Autonomous Communities, makes of this kind of institutions.

The clear lack of a specific regulation for commissions of inquiry in the legislations of local government, and its poorly development in the municipal organic rules where they figure, entails that its analysis may go through the study of these bodies within the parliamentary nature, state-Congress and Senate-and autonomic, and that it is necessary its proper contextualization in the municipal regime.
\end{abstract}

Key words

Municipalities, commissions of inquiry, research instruments, appearance, opinion, conclusions. 


\section{CONCEPTO Y NATURALEZA JURÍDICA}

La primera referencia que se encuentra en nuestra historia constitucional a las comisiones de investigación es la actual Constitución Española de 1978 (CE), aunque no ha sido una figura desconocida en el parlamentarismo español a pesar de su ausencia de los textos constitucionales, pues se las ha considerado un subgénero de las comisiones especiales -que sí gozan de regulación reglamentaria-, y sin que esta falta de previsión normativa expresa haya sido un obstáculo para su creación como expresión del poder de investigación que implícitamente le corresponde a las Cámaras.

La doctrina constitucionalista tiende a señalar que la investigación parlamentaria constituye un poder instrumental de las distintas funciones que la Constitución atribuye a las Cámaras. No obstante, dentro de esta naturaleza instrumental o auxiliar, se encuentran dos tesis contrapuestas, esto es, la de los que consideran que la investigación parlamentaria se encuadra dentro de las funciones de información e inspección de la Cámaras, y aquella otra que configura la investigación parlamentaria como un instrumento de control parlamentario sobre el poder ejecutivo.

De estas dos tesis, quienes defienden que la investigación parlamentaria es un mecanismo autónomo de inspección e información parlamentaria de diferente naturaleza y finalidad que los articulados para ejercer el control parlamentario -preguntas e interpelaciones-, justifican su posición en los siguientes argumentos'.

En primer lugar, la diferente ubicación sistemática en la Constitución de las preguntas e interpelaciones, situadas en el apartado dedicado a las relaciones entre el Gobierno y las Cortes Generales, y las comisiones de investigación que encuentran acomodo en el que se refiere a las Cortes Generales. En este sentido, la base de la investigación parlamentaria se hallaría en la atribución genérica de potestades y competencias que la Constitución otorga a las Cortes y no en una específica función de control.

Asimismo, señalan la diferencia entre los requisitos que se exigen para la constitución y régimen de funcionamiento colegiado de este tipo de comisiones, pues, mientras que las preguntas e interpelaciones son iniciativas que se toman a instancia de un solo parlamentario, las comisiones de investigación tienen una composición plural y representativa de la composición de la Cámara en cuestión, lo que se

1 Entre otros: Carlos Álvarez-Ossorio Fernández (1995), Las comisiones de investigación: ¿actos de control o instrumentos de información parlamentaria? VI Jornadas de Derecho Parlamentario. Problemas actuales del control parlamentario. Madrid. Publicaciones del Congreso de los Diputados. Enrique Lucas Murillo de la Cueva (1986), “Las Comisiones de investigación de las Cortes"; Revista de la Facultad de Derecho de la Universidad Complutense, núm. 10, y Fernando Santaolalla López (1982), El Parlamento y sus instrumen-

90 tos de información. Editoriales de Derecho Reunidas. 
entiende como una actuación conjunta de todo el Parlamento y no de uno sólo de sus miembros.

Por otro lado, ponen de relieve que el sujeto investigado por las comisiones de investigación no es únicamente la acción del gobierno puesto que, a tenor del artículo 76 de la Constitución y la Ley Orgánica 5/1984 que desarrolla las comparecencias ante ellas, puede serlo cualquier sujeto que esté relacionado con el objeto de la investigación.

Estos argumentos llevan a insistir en la idea de que la investigación parlamentaria es una actividad autónoma que cumple la función de garantía constitucional de la soberanía del pueblo y que tiene su apoyo en la alta representación de las Cortes Generales, sin que ello sea óbice, dado el carácter versátil y polivalente de este mecanismo, para que a través de una investigación parlamentaria se produzca una situación de desgaste que lleve a la exigencia de responsabilidad política.

Según uno de los partidarios de esta tesis, el profesor Álvarez-Ossorio, las comisiones de investigación se podrían definir como aquellos instrumentos al servicio de las Cortes Generales, en tanto que representantes del pueblo español, que sirven para la fiscalización, seguimiento e información de todos aquellos asuntos o problemas que afecten a la sociedad y que por su relevancia puedan ser considerados por las Cortes de interés público².

En el otro lado, quienes defienden que las comisiones de investigación son un mecanismo de control parlamentario circunscriben la finalidad de la información parlamentaria al control de la acción del Gobierno y, por extensión, de toda la Administración Pública de la que es responsable ${ }^{3}$. Argumentan que la ubicación sistemática del precepto no constituye razón suficiente para fundamentar que la naturaleza de estos órganos es la de meros instrumentos de información, pues cabe entender que responde a la consideración de las comisiones de investigación desde el punto de vista organizativo de la Cámara, por lo que es lógico su tratamiento a continuación de la previsión de que ésta funcione en pleno y en comisiones, sin que ello sea un obstáculo para su configuración como órgano de control parlamentario ${ }^{4}$.

Sea cual sea la tesis que desde un punto de vista puramente teórico doctrinal más nos convenza, lo cierto es que las comisiones de investigación, a la vista de su

2 Carlos Álvarez-Ossorio; Op. cit.; p. 809.

3 Entre otros: Joaquín García Morillo (1985), El control Parlamentario del Gobierno en el ordenamiento español. Madrid. Publicaciones del Congreso de los Diputados. Manuel Aragón Reyes (1986), "El control Parlamentario como Control Político"; Revista de Derecho Político de la UNED, núm. 23, y Alfonso Arévalo Gutiérrez (1995), "Las Comisiones de investigación de las Cortes Generales y de las Asambleas legislativas de las Comunidades Autónomas”; Revista Española de Derecho Constitucional.

4 María Torres Bonet (1998); Las comisiones de investigación, instrumento de control parlamentario del gobierno. Madrid. Publicaciones del Congreso de los Diputados, pp. 87. 
concreción reglamentaria y de la práctica parlamentaria, se han erigido en un medio o instrumento importante que se pone a disposición de los grupos políticos para supervisar la acción de gobierno y que, si bien su objetivo es la búsqueda de la verdad sobre un asunto que ha llamado la atención de la sociedad, suelen convertirse en un medio de confrontación política orientado a la opinión pública y en ocasiones, incluso, pueden finalizar con exigencias de responsabilidad política al ejecutivo.

En este contexto, los rasgos o notas características de las comisiones de investigación podrían resumirse en las siguientes:

- Su carácter de órganos auxiliares del Parlamento, que por su composición y objetivos cumplen una tarea netamente política.

- Su temporalidad, que las distingue del resto de comisiones, pues nacen con la finalidad de investigar un asunto determinado y una vez cumplido su cometido se disuelven.

- Su actividad, que se orienta a la inspección de los indicios de actuación anómala o de funcionamiento defectuoso de las instituciones y servicios dependientes del ejecutivo.

\section{RÉGIMEN NORMATIVO}

Las comisiones de investigación de las Cortes Generales encuentran su amparo legal en el propio texto constitucional, concretamente es el artículo $76 \mathrm{CE}^{5}$ el que establece su marco de actuación y el que recoge la obligación de comparecer ante ellas. Esta obligación de comparecencia de los ciudadanos ante las comisiones de investigación ha sido objeto de desarrollo a través de la Ley Orgánica 5/1984, de 24 de mayo, que fija el marco de garantías para su ejercicio.

A partir de estas normas, han sido los Reglamentos del Congreso y del Senado los que se han encargado de pormenorizar el funcionamiento de estas comisiones $^{6}$.

5 El artículo 76 de la CE recoge la figura de las comisiones de investigación en los siguientes términos:

1. El Congreso y el Senado, y en su caso, ambas Cámaras conjuntamente, podrán nombrar Comisiones de investigación sobre cualquier asunto de interés público. Sus conclusiones no serán vinculantes para los Tribunales, ni afectarán a las resoluciones judiciales, sin perjuicio de que el resultado de la investigación sea comunicado al Ministerio Fiscal para el ejercicio, cuando proceda, de las acciones oportunas.

2. Será obligatorio comparecer a requerimiento de las Cámaras. La ley regulará las sanciones que puedan imponerse por incumplimiento de esta obligación."

6 Reglamento del Congreso de los Diputados de 10 febrero 1982 (BOE de 5 marzo 1982, núm. 55 , pp. 5765). Reglamento del Senado, Texto Refundido de 3 de mayo de 1994 (BOE de 13 de mayo de 1994,
núm. 114, pp. 14687). 
En el caso de las asambleas legislativas de las Comunidades Autónomas, no existe una disposición en la CE semejante a la de las Cortes Generales; sin embargo, las comisiones de investigación han sido una constante en el ámbito de los parlamentos autonómicos desde el principio de su existencia, sin que ello haya supuesto grandes debates, pues existe una opinión doctrinal casi unánime 7 a la hora de reconocer a dichas asambleas un poder implícito de investigación fundamentado en su autonomía política y legislativa. Mayor problema ha supuesto la posible sanción ante el incumplimiento de la obligación de comparecer, que ha provocado en este punto una reforma del Código Penal para admitir tal sanción en los supuestos de obstaculización a la investigación de los parlamentos autonómicos.

Puesto que sólo algunos de los Estatutos de Autonomía hacen referencia a estos órganos parlamentarios su regulación corresponde casi exclusivamente a los reglamentos de las respectivas asambleas ${ }^{8}$.

Por lo que respecta a los municipios, la legislación local no alude expresamente a las comisiones de investigación, con la dificultad añadida de que, a pesar de los intentos de parlamentarización llevados a cabo por las últimas reformas de la legislación básica local, los plenos de los ayuntamientos no pueden considerarse en puridad un parlamento en el sentido que lo son, en base al principio de la división de poderes y a su reconocimiento constitucional, las Cortes Generales o las asambleas legislativas de las Comunidades Autónomas; no obstante, la misma existencia de un poder de actuación implícito, connatural a las funciones de inspección, control y supervisión del gobierno municipal atribuidas al órgano plenario fundamentaría la posibilidad de que estas comisiones sean una especie de aquellos órganos que con esa denominación, u otra, tengan atribuido el seguimiento de la gestión del Alcalde, la Junta de Gobierno Local y los concejales que ostenten delegaciones, tal como prevé el artículo 20.1.c) de la Ley 7/1985, de 2 de abril, Reguladora de las Bases del Régimen Local (LRBRL), para los municipios de régimen general, y específicamente para las comisiones en los municipios de gran población el artículo 122.4.b) de la misma Ley 9 .

No obstante, el que pueda justificarse la creación de este tipo de comisiones en el ámbito municipal, con fundamento en la autonomía constitucionalmente garanti-

7 Por todos, Joaquín García Morillo (1995); El control parlamentario de las Cortes Generales y las Asambleas Legislativas de las Comunidades Autónomas: autonomía y comisiones de investigación. VI Jornadas de Derecho Parlamentario. Problemas actuales del control parlamentario. Madrid. Publicaciones del Congreso de los Diputados.

8 Los Estatutos de Autonomía de Aragón, Asturias, Baleares, Cantabria, Castilla-La Mancha, Murcia y Valencia únicamente aluden a las comisiones de investigación para destacar su carácter de comisiones especiales.

9 El artículo 20.1.c) determina que corresponderán a las comisiones las funciones de "seguimiento de la gestión del Alcalde y de su equipo de gobierno, sin perjuicio del superior control y fiscalización que, con carácter general, corresponde al Pleno”. El artículo 22.2 a) de la misma Ley, establece que al Pleno del Ayuntamiento le corresponde "el control y la fiscalización de los órganos de gobierno". 
zada y los poderes implícitos reconocidos al Pleno como máximo órgano de representación política, no significa que pueda aplicarse, sin más, el régimen jurídico de ámbito parlamentario, sino que será necesario un trabajo interpretativo y contextualizador que permita integrar dicho instituto en el funcionamiento del órgano de representación municipal que, aún teniendo la legitimidad democrática que le otorga el carácter electo de sus miembros, no se apoya en los mismos fundamentos constitucionales que las cámaras estatales o autonómicas.

En cualquier caso, correspondería a los reglamentos orgánicos municipales, en previsión de que se puedan crear comisiones de investigación, recoger en su texto el marco jurídico regulador de esos órganos ${ }^{10}$.

\section{EL OBJETO DE LA INVESTIGACIÓN}

\section{Los asuntos de interés público y la actividad del ejecutivo}

El artículo 76 CE establece un concepto indeterminado sobre lo que puede ser objeto de investigación parlamentaria: “cualquier asunto de interés público”, requisito éste que se reproduce en casi todos los reglamentos de los parlamentos autonómicos que prevén expresamente la existencia de comisiones de investigación.

Sobre el contenido que debe atribuirse al concepto, resulta interesante una sentencia del Tribunal Constitucional" que se refiere a esta locución afirmando que "la vía natural de expresión de la idea y contenido que la sociedad tiene del interés público vigente en cada caso, cuando se trata de la adopción de acuerdos que llevan consigo opiniones de naturaleza primaria o prevalentemente política (... ) la constituye la voluntad mayoritaria de los órganos representativos formada en debate público y a través de los procedimientos jurídicos establecidos". Esto es, según la jurisprudencia constitucional, el interés público consiste en cada caso en aquello que como tal considere el órgano legitimado para adoptar la decisión. Serán los órganos parlamentarios, y en el caso de los municipios los Plenos de los Ayuntamiento en cuanto depositarios de la voluntad popular, los legitimados para decidir, si se detectan o no las

10 A título de ejemplo, así lo han hecho, con mayor o menor detalle en su regulación: el Reglamento Orgánico del Ayuntamiento de Barcelona (artículo 35); el Reglamento Orgánico del Ayuntamiento de Cartagena (artículo 41); el Reglamento Orgánico del Pleno y sus Comisiones de Castellón de la Plana (artículo 117); el Reglamento Orgánico del Pleno del Ayuntamiento de Madrid (artículo 138); el Reglamento Orgánico del Pleno del Ayuntamiento de Málaga (artículo 172); el Reglamento Orgánico del Ayuntamiento de Móstoles (artículos 185 a 188); el Reglamento Orgánico del Pleno del Ayuntamiento de Oviedo (artículo 104); el Reglamento Orgánico del Ayuntamiento de Palma de Mallorca (artículo 130); el Reglamento Orgánico del Pleno del Ayuntamiento de San Sebastián (artículo 149); el Reglamento Orgánico del Pleno de Santa Cruz de Tenerife (artículo 25); el Reglamento Orgánico del Ayuntamiento de Sevilla (artículos 114 a 117); el Reglamento Orgánico del Pleno del Ayuntamiento de Toledo (artículo 129); el Reglamento Orgánico del Ayuntamiento de Valladolid (artículo 52); el Reglamento Orgánico del Pleno de Vitoria (artículo 156); el Reglamento Orgánico del Ayuntamiento de Zamora (artículo 69) y el Reglamento Orgánico del Ayuntamiento de Zaragoza (artículo 122).

11 Sentencia 130/1991, de 6 de junio. 
características que convierten un asunto en objeto de interés público y, por tanto, si está justificada la creación de una comisión de investigación.

La delimitación del objeto de la investigación -asuntos de interés público- la relacionamos con el fin perseguido con la creación de estas comisiones -control de la acción del Gobierno-, es fácilmente deducible que las mismas deben conocer básicamente de actos del Gobierno sobre los cuales se suscite un interés público al cuál la Cámara deba dar respuesta.

En consecuencia, a la hora de determinar al ámbito material de actuación de las comisiones de investigación deberán considerarse conjuntamente dos tipos de criterios, uno adjetivo o formal de decisión adoptada por la Cámara siguiendo el procedimiento reglamentariamente establecido, y otro sustantivo o material que obedece a la necesaria conexión de la Cámara de representación con la opinión pública, como garantía de la vinculación entre ambas ${ }^{12}$.

\section{El sujeto destinatario de la investigación}

Si partimos del concepto de las comisiones de investigación como meros órganos de información de las Cámaras, es claro que la información puede recaer sobre el funcionamiento y la gestión de cualesquiera órganos constitucionales que hayan generado aquellas situaciones que se pretendan enjuiciar políticamente. Si se aborda la cuestión desde la perspectiva de las comisiones de investigación como órganos de control político de la actividad del ejecutivo, los sujetos pasivos de la investigación serán los poseedores de responsabilidades públicas, de naturaleza política, bien sea en el Gobierno o en la Administración de él dependiente.

Hay quién considera, dando un paso más allá, que, junto con la actuación del Gobierno y la Administración, son admisibles incluso las investigaciones en el ámbito privado, siempre que tengan un mínimo de repercusión social que las dote de interés público, y ello porque el Parlamento está destinado a representar los intereses del pueblo en su conjunto y, para cumplir esta función, puede que le resulte necesario indagar directamente en materias que no tengan que ver con las actividades del resto de los poderes del Estado pero que por su influencia en la sociedad si puedan considerarse como de interés público ${ }^{13}$.

\section{Características}

Por lo que se refiere a las características de la actividad investigada, debe poner de manifiesto una actitud negligente u omisión irresponsable de los poderes públi-

12 María Torres Bonet; Op. cit., p. 110.

13 Ignacio Torres Muro (1998), Las comisiones parlamentarias de investigación. Madrid. Cuadernos y debates del Centro de Estudios Políticos y Constitucionales, pp. 77 y ss. 
cos, una actividad pública irregular que la comisión debe esclarecer e, indirectamente, reorientar.

A este comportamiento irregular debe sumarse una nota de complejidad en el asunto a indagar, que impida o dificulte su esclarecimiento mediante otros instrumentos de control parlamentarios menos complejos desde un punto de vista organizativo, como las preguntas y las interpelaciones.

\section{Delimitación de la actividad investigadora}

La distribución de competencias inherente a la organización territorial de nuestro Estado como Estado autonómico implica, entre otros factores, una distribución de funciones propias que afecta también a la actividad de los parlamentos y, en consecuencia, a la de las comisiones de investigación. Cabe, así, plantearse la posibilidad de que en las Cortes Generales se creen comisiones de investigación relativas a cuestiones circunscritas al ámbito de una Comunidad Autónoma, así como también cabe una coincidencia de objetos entre comisiones de investigación de las Cortes Generales y de alguna asamblea autonómica.

En el primer supuesto, esto es, comisiones constituidas en las Cortes Generales sobre asuntos radicados en las Comunidades Autónomas, hay que distinguir entre aquellos cuya responsabilidad corresponda al ejecutivo estatal de los que supongan una fiscalización y control del ejecutivo autonómico. Los autores coinciden en entender que si la investigación recae en hechos o actividades acaecidos en una Comunidad Autónoma pero sobre una materia cuya competencia corresponde al Estado, la responsabilidad sería del Gobierno central y ello haría factible la creación de una comisión de investigación en las Cortes Generales para indagar sobre los hechos. Si, por el contrario, el asunto se corresponde con una competencia que corresponde a una Comunidad Autónoma, no sería posible la fiscalización por las Cortes Generales de los órganos ejecutivos autonómicos, pues ello conculcaría la autonomía política de las instancias autonómicas que, por definición, conlleva la prohibición de cualquier control político ${ }^{14}$. El control y fiscalización de los órganos de gobierno autonómicos corresponde exclusivamente a las asambleas legislativas respectivas.

Sin embargo, cabría la posibilidad de que una situación determinada pudiera dar lugar a la exigencia de responsabilidades políticas tanto del ejecutivo central como del autonómico. En este caso, se entiende que no existe obstáculo jurídico a la coincidencia temporal de comisiones de investigación sobre unos mismos hechos en los

14 Los Reglamentos parlamentarios de algunas Comunidades Autónomas, como es el caso de Madrid, Valencia y La Rioja, subrayan de una u otra forma la necesidad de que el ámbito material de las comisiones de investigación esté comprendido dentro del marco de competencias que les es propio, lo que resulta coherente con el reparto para actuar sobre determinadas materias que conlleva el Estado autonómico. 
dos niveles territoriales, pues ambas indagan con el fin de detectar posibles responsabilidades en instituciones distintas ${ }^{15}$.

Si variamos de nivel territorial y en vez de hablar de Estado-Comunidades Autónomas nos referimos a los municipios, el escenario sería el mismo. La autonomía que la CE (artículo 137) les reconoce para "la gestión de sus respectivos intereses", supone una habilitación y a la vez un límite en cuanto a los asuntos susceptibles de investigación. Habilitación en tanto que las comisiones de investigación podrán actuar respecto de aquellas actividades que estén dentro del ámbito competencial del respectivo municipio y estén relacionadas con el espacio de responsabilidad pública ejercido por los miembros del gobierno municipal, y límite en cuanto no podrán crearse para esclarecer o investigar asuntos cuya competencia corresponda a otras instancias territoriales o supongan una fiscalización de otros órganos de gobierno ${ }^{16}$.

Asimismo, como ha quedado dicho, podría darse el caso de una coincidencia temporal sobre unos mismos hechos en diferentes niveles territoriales, incluido el municipal, cuando la exigencia de responsabilidades sea concurrente en diferentes instituciones.

\section{RÉGIMEN DE FUNCIONAMIENTO}

En la práctica, los mayores conflictos que se producen en el seno de las comisiones de investigación tienen que ver con la organización y desarrollo de sus trabajos, en donde hay que compaginar la premura en la consecución de los objetivos marcados con el rigor y la garantía de los derechos de los afectados.

Uno de los factores sobre los que hay que hacer más hincapié cuando se crea una comisión de investigación es la necesidad de que tengan los suficientes medios personales y materiales para que puedan prosperar en sus cometidos. Los poderes extraordinarios que se reconocen a estos órganos debe tener su correlativo en los

15 Joaquín García Morillo. “Principio de autonomía y control parlamentario: el supuesto de las comisiones de investigación”, Revista Vasca de Administración Pública, num. 44: p. 145.

16 Son pocos los Reglamentos Orgánicos municipales que delimitan el campo de actividad de las comisiones de investigación. Como ejemplos: el Reglamento Orgánico del Pleno de Santa Cruz de Tenerife, que determina que "se podrá acordar la creación de Comisiones de Investigación sobre cualquier asunto de interés público” (artículo 25); en la misma línea el Reglamento Orgánico del Ayuntamiento de Sevilla establece que "podrán constituirse Comisiones para investigar cualquier asunto que se entienda merece especial atención municipal” (artículo 114); el Reglamento del Ayuntamiento de Móstoles (Madrid), que, a nuestro entender con acierto, delimita ese interés al círculo de los propios del municipio cuando establece que se podrá acordar la creación de una "Comisión Especial de Investigación sobre cualquier asunto de interés municipal” (artículo 185). Curiosa es la previsión del Reglamento de Vitoria que señala como funciones exclusivas de las comisiones de investigación "el seguimiento y control de la gestión del Alcalde y su equipo de gobierno" (artículo 156), toda vez que esta es una función general atribuida a las Comisiones del Pleno por la propia Ley de Régimen Local (artículo 122.4.b). 
instrumentos que se les conceden para desarrollar eficazmente su trabajo. Sólo a partir de que se le dote de los recursos necesarios estaría la comisión en disposición de comenzar su actividad y, éste, es un obstáculo más con el que se topan las comisiones indagatorias municipales, pues, así como las cámaras parlamentarias tienen sus propios recursos y pueden disponer presupuestariamente de ellos, los plenos tendrán los medios que, para el caso extraordinario de una actividad investigadora, el ejecutivo municipal tenga a bien a asignarles.

De acuerdo con los reglamentos de las Cortes Generales, y de la mayoría de los de las asambleas y parlamentos autonómicos, las comisiones de investigación conformarán su actividad según las normas generales de funcionamiento de las demás comisiones y las específicas que hayan podido establecerse para ellas.

En defecto de esta previsión reglamentaria específica, la ordenación de las sesiones de los órganos de encuesta se llevará a cabo de conformidad con las normas de procedimiento que dicte el presidente de la cámara de acuerdo con la comisión. Esta habilitación se encuentra en el Reglamento del Congreso ${ }^{17}$ y en gran parte de los de las asambleas autonómicas, aunque en alguno de estos reglamentos la función de dictar, en su caso, las oportunas normas de procedimiento no se atribuye al Presidente sino a la Mesa de la Cámara, oída la Junta de Portavoces ${ }^{18}$.

Además, la actuación de las comisiones de investigación no está sometida únicamente a normas reglamentarias pues, como tendremos ocasión de ver más adelante, existen también disposiciones legales que inciden en su funcionamiento, tales como la Ley Orgánica 5/1984 relativa al régimen de las comparecencias o el Real Decreto-Ley 5/1994 que regula la obligación de comunicar determinados datos a su requerimiento.

Por último y no por ello menos importante, está el acuerdo del Pleno de la Cámara por el que se crea la comisión y que, como también veremos, incluye aspectos tan relevantes como la determinación del número de miembros que la componen, el número de ellos que se asigna a cada grupo parlamentario, el plazo de sus trabajos, etc.

La actividad de la comisión puede sistematizarse en tres fases: una primera que incluiría la creación de la comisión, su constitución, la aprobación del Plan de trabajo y el requerimiento de documentación y presencia de personas para ser oídas. Una segunda, que se correspondería con el desarrollo propiamente dicho de la actividad indagatoria, esto es: el estudio y valoración de la documentación recibida y las decla-

17 El artículo 52.3 del Reglamento del Congreso, establece que "La Presidencia de la Cámara, oída la Comisión, podrá dictar las oportunas normas de procedimiento".

18 Reglamentos del Parlamento de Canarias, de las Cortes de Castilla y León y de Navarra (artículos $50.3,50.4$ y 62.3, respectivamente). 
raciones de los comparecientes; y una última fase que sería aquella en la que se elabora el dictamen que recoge las conclusiones de la investigación.

A continuación se desarrolla esta estructura básica, conforme a la cual las comisiones de investigación despliegan sus funciones inspectoras.

\section{CREACIÓN}

La creación de una comisión de investigación pasa por una serie de etapas sucesivas que pueden concretarse en: la iniciativa de creación, su admisión y la votación de la propuesta por la cámara para, en caso de prosperar, determinar su constitución en el correspondiente acuerdo.

\section{Iniciativa}

La legitimación para presentar una iniciativa de creación de una comisión de investigación varía según los diferentes parlamentos o asambleas. Así, en el Congreso de los Diputados dicha iniciativa se reserva al Gobierno, la Mesa, dos grupos parlamentarios o la quinta parte de los diputados (artículo 52.1 del Reglamento del Congreso); en el Senado los titulares de la propuesta son el Gobierno o veinticinco senadores que no pertenezcan al mismo grupo parlamentario; en las asambleas de las comunidades autónomas la variedad va, desde la propuesta de la dos quintas partes de sus miembros (artículo 75 del Reglamento de la Asamblea de Madrid), a la de dos grupos parlamentarios, la quinta parte de los miembros del Parlamento o la Mesa (Artículo 85 del Reglamento del Parlamento de Cataluña); el Consejo de Gobierno, un grupo parlamentario o la décima parte de los miembros de la Cámara (artículo 52 del Reglamento del Parlamento de Andalucía); etc.

Como puede observarse, tanto en el Congreso como en el Senado y en las asambleas de las Comunidades Autónomas, la iniciativa no se atribuye a un parlamentario individual sino a un conjunto de ellos o a los grupos parlamentarios. Esta mayor cualificación para instar una investigación ha sido recogida, asimismo, por aquellos reglamentos orgánicos que han regulado estos instrumentos de control en el ámbito municipal. Como ejemplo: los reglamentos de Castellón de la Plana, Málaga, Madrid, Oviedo, Palma de Mallorca y Toledo, atribuyen la iniciativa al Alcalde, a la Junta de Gobierno Local y a un grupo municipal; los de San Sebastián y Santa Cruz de Tenerife, al Alcalde, la Junta de Gobierno Local y a dos grupos que integren al menos a un tercio de los concejales; el Reglamento de Barcelona, junto al Alcalde y la Comisión de Gobierno, atribuye la legitimación a tres grupos políticos y, el de Zaragoza, al Alcalde, la Junta de Gobierno y a dos grupos o las dos quintas partes de los miembros del Pleno. 
Por lo que se refiere a la forma que debe adoptar la propuesta, los reglamentos parlamentarios, al igual de los orgánicos de los Ayuntamientos, no lo especifican. No obstante, con independencia de la denominación que reciba, deberá ser un tipo de iniciativa a través de la cual los legitimados puedan instar del órgano plenario la adopción de un acuerdo resolutivo. Así, en el Congreso, su Reglamento, prevé (artículo 193) que se puedan presentar proposiciones no de ley para formular propuestas de resolución a la Cámara. En el ámbito municipal, según la terminología del Reglamento de Organización, Funcionamiento y Régimen Jurídico de las Entidades Locales sería una proposición, definida por el ROF como una propuesta que se somete al Pleno, que contiene una parte expositiva o justificación y un acuerdo a adoptar (artículo 97).

\section{Admisión de la propuesta}

En el ámbito parlamentario la calificación y admisión de las iniciativas corresponde a la Mesa. Su intervención consiste en el control de su adecuación a los reglamentos de las cámaras, lo que se traduce en la comprobación de sus requisitos formales y materiales.

En el Congreso de los Diputados, la propuesta que inste la creación de una comisión de investigación deberá presentarse por escrito ante la Mesa de la Cámara (artículo 194.1 del Reglamento del Congreso), la cual se pronunciará sobre la admisibilidad de la proposición. Lo mismo ocurre en el Senado y en las asambleas de las Comunidades Autónomas, en donde se atribuye a ese órgano colegiado la función de calificación y admisión a trámite de los escritos y documentos de índole parlamentaria. De la doctrina del Tribunal Constitucional se deduce que las labores de calificación y admisión a trámite de documentos por parte de la Mesa de las Cámaras consiste principalmente en un examen jurídico en cuyo ejercicio le está vedado en todo caso el juicio de oportunidad política ${ }^{19}$. En relación con las propuestas de creación de una comisión de investigación, el control de admisibilidad por parte de la Mesa debe referirse, pues, al cumplimiento de los requisitos formales de legitimación de los presentadores, así como a su adecuación al objeto determinado por la CE: cualquier asunto de interés público.

La naturaleza fiscalizadora de la Mesa, ha determinado que los reglamentos parlamentarios establezcan, en relación con la función de calificación y admisión a trámite de documentos, un procedimiento de solicitud de reconsideración de la misma, para el caso de disconformidad con la decisión adoptada por aquella y que no impide

19 El Auto 428/1989, del Tribunal Constitucional, define el control de admisión por parte de la Mesa como "un control de legalidad que se efectúa en función de un canon estrictamente normativo, no político o de oportunidad". 
su revisión posterior por parte del Tribunal Constitucional a través del recurso de amparo directo contra actos parlamentarios no legislativos, previsto en el artículo 42 de la Ley Orgánica del Tribunal Constitucional ${ }^{20}$.

En el ámbito municipal el panorama es un tanto diferente. En primer lugar, no existe, en general ${ }^{21}$, la figura de la Mesa con las atribuciones descritas, de tal forma que la decisión de admitir o no una iniciativa de este tipo pasa, como el resto de iniciativas, por que el órgano que tiene atribuida la función de determinar los asuntos que han de ser incluidos entre los que se van a tratar en una sesión del órgano plenario, opte por incluirla o no en el orden del día de la sesión. Según la normativa de régimen local, la confección del orden del día corresponde al Alcalde-Presidente ${ }^{22}$, quien será pues, en definitiva, el responsable de decidir si en la relación de puntos a debatir en la sesión se incluye la propuesta de creación de una comisión de investigación. Ello, sin perjuicio de que, como es práctica habitual -formalizada en algunos reglamentos orgánicos- se oiga previamente a la Junta de Portavoces o a los portavoces de los grupos políticos municipales.

En segundo lugar, tampoco existe un procedimiento similar al de reconsideración previsto en sede parlamentaria. No obstante, aunque no hay un mandato imperativo que obligue a introducir en el orden del día todas las propuestas que se hagan, no es menos cierto que el ejercicio de tal actividad, como cualquier otra tendente a dirigir y ordenar el debate en las sesiones, tiene un marco legal y reglamentario al que debe ajustarse. Por tanto, si alguno de los miembros corporativos entiende que la actuación de algún órgano municipal no se ajusta a la legalidad vigente y que con ello se le impide o restringe el ejercicio de su derecho a la participación en los asuntos públicos, tal actividad puede ser objeto de impugnación ante la jurisdicción contenciosa, siendo posible, asimismo, interponer el potestativo recurso administrativo de reposición previamente a su impugnación judicial.

20 Este precepto dispone que "Las decisiones o actos sin valor de Ley, emanados de las Cortes o de cualquiera de sus órganos, o de las Asambleas legislativas de las Comunidades Autónomas o de sus órganos, que violen derechos y libertades susceptibles de amparo constitucional, podrán ser recurridos dentro del plazo de tres meses desde que, con arreglo a las normas internas de las Cámaras o Asambleas, sean firmes".

21 Como excepción a lo que es habitual, el Ayuntamiento de Santa Cruz de Tenerife si tiene previsto en su Reglamento Orgánico la existencia de una Mesa del Pleno, a la que se atribuye, entre otras, la función de calificar los escritos y documentos referidos a asuntos de la competencia del Pleno, así como declarar la admisibilidad o inadmisibilidad de los mismos mediante acuerdo motivado (artículo 18).

22 El Texto Refundido de las Disposiciones Legales vigentes en materia de Régimen Local (TRRL) se refiere a él en su artículo 47.2 al señalar que "Salvo en casos de urgencia, no se tratarán más asuntos que los señalados en el orden del día de cada sesión, que formará el Presidente y se distribuirá a los miembros de la Corporación con antelación mínima de dos días hábiles”. En el mismo sentido, el ROF dispone que "El orden del día de las sesiones será fijado por el Alcalde o Presidente asistido de la Secretaría” (artículo 82). 


\section{Acuerdo de creación}

Como sabemos, las comisiones de investigación no son órganos que formen parte de la estructura permanente de las Cámaras, sino que deben su existencia a una decisión específica de sus Plenos. Se trata, por tanto, de una potestad de la que se hace uso según las circunstancias ${ }^{23}$.

En el ámbito estatal, la creación de estas comisiones adopta la forma de resolución parlamentaria que, junto con las mociones, se inscribe en la categoría de actos no legislativos del Parlamento y constituye el instrumento mediante el cual la Cámara manifiesta expresamente su voluntad a través de la adopción de una decisión.

La resolución de creación suele incluir varios aspectos importantes: el objeto de la comisión; el número de miembros que la componen, el tiempo de duración de los trabajos, etc. ${ }^{24}$. Posiblemente, el más importante es el que se refiere a la materia sobre la cual versará la investigación ${ }^{25}$, que deberá establecerse de forma clara y bien delimitada, así como sus fines y objetivos, para evitar cualquier duda acerca de la finalidad que debe guiar sus planes y que resultará determinante a la hora de elaborar el plan de trabajo de la comisión, una vez que se haya constituido ${ }^{26}$.

23 No obstante, hay algún caso en el que se establece la obligación de crear una comisión de investigación, como en el Reglamento del Parlamento de Cataluña, que determina que la creación de una comisión de investigación será preceptiva cuando lo soliciten una tercera parte de los diputados o tres grupos parlamentarios, aunque los proponentes sólo pueden presentar una propuesta vinculante cada año (artículo 58.3).

24 El Reglamento de la Asamblea de Madrid, especifica que la propuesta de creación deberá contener "las reglas básicas sobre la composición, organización y funcionamiento de la comisión de investigación, así como el plazo de finalización de sus trabajos” (artículo 75.1).

25 María Torres Bonet; Op. cit. p. 217. Según esta autora "El objeto de la Comisión de investigación está integrado por el sector de la realidad que se investiga y por la finalidad que se persigue con dicha indagación. El acto de creación debe contener necesariamente una asignación finalista concreta de dicha comisión de investigación, pues su existencia está ordenada a la satisfacción de una determinada finalidad...".

26 Como ejemplo de un acuerdo de creación, el de la Comisión de investigación sobre el 11 de marzo de 2004 (Boletín del Congreso de los Diputados, núm. 20, de 24 de mayo de 2004, p. 2) es del siguiente tenor:

“1. Se acuerda la creación de una Comisión de Investigación que tenga por objeto, de acuerdo con lo expresado en su integridad en las exposiciones de motivos de las propuestas presentadas el 6 de mayo, lo siguiente:

a) Esclarecer la verdad acerca de los hechos sucedidos los días 11 al 14 de marzo, así como los antecedentes y consecuentes que resulten coherentes con aquella finalidad.

b) Esclarecer los acontecimientos anteriores y posteriores a los atentados del 11 de marzo vinculados con éstos y las actuaciones que han realizado sobre ellos los poderes del Estado.

2. Composición:

La Comisión estará compuesta por cinco Diputados del Grupo Parlamentario Socialista del Congreso, cinco del Grupo Parlamentario Popular en el Congreso, uno del Grupo Parlamentario Catalán (Convergència i Unió), uno del Grupo Parlamentario de Esquerra Republicana (ERC), uno del Grupo Parlamentario Vasco (EAJ-PNV), uno del Grupo Parlamentario de Izquierda Verde-Izquierda Unida-Iniciativa per Catalunya Verds, uno del Grupo Parlamentario de Coalición Canaria y uno del Grupo Parlamentario Mixto.

Aquellos Grupos con un representante en la Comisión podrán designar un suplente.

Si hubiese votaciones, el voto será ponderado. 
En cuanto a la votación de la propuesta, tanto en el Congreso como en el Senado, así como en las asambleas legislativas de las Comunidades Autónomas, la mayoría que se exige para su aprobación es, a falta de previsión específica, la mayoría simple.

\section{Plazo:}

La Comisión habrá de culminar sus trabajos en un plazo de dos meses desde su constitución, pudiendo ampliarse dicho plazo por acuerdo de aquélla. La Comisión elevará al Pleno del Congreso para su debate y aprobación el correspondiente escrito de conclusiones.

El calendario de sesiones, así como su método de trabajo y las comparecencias a solicitar, será acordado por la Comisión, una vez sea constituida".

En el ámbito municipal, mucho más escuetamente, el Ayuntamiento de Vitoria, en la sesión ordinaria del Pleno de 22 de diciembre de 2006, adoptó el acuerdo de:

“1. Constituir con carácter de urgencia una comisión especial denominada Comisión de investigación de irregularidades urbanísticas.

2. Esta comisión especial está regulada en el artículo 153 y siguientes del Reglamento Orgánico del Pleno.

3. El objeto de la citada comisión de investigación serán las irregularidades urbanísticas detectadas en las viviendas bioclimáticas de labiondo (parcela EHU-1) y en las siete viviendas unifamiliares de Ali, así como cualquier otra irregularidad que emane de dicha investigación".

Otros ejemplos de acuerdos de creación pueden encontrarse en las siguientes referencias:

- Comisión de Investigación en el Congreso de los Diputados sobre la gestión de los fondos presupuestarios asignados a la Dirección General de la Guardia Civil, mientras fue Director General Don Luis Roldán. Acuerdo de creación adoptado por el Pleno de la Cámara. Boletín Oficial del Congreso de los Diputados, serie E; núm. 45, de 18 de febrero de 1994, p. 1. En línea: <http://www.congreso.es>.

- Comisión de Investigación en el Congreso de los Diputados para analizar la política desarrollada mediante ayudas comunitarias al cultivo del lino. Acuerdo de creación adoptado por el Pleno de la Cámara. Boletín Oficial del Congreso de los Diputados, serie D, General; núm. 445, de 7 de junio de 1999, p. 2. En línea: <http://www.congreso.es>.

- Comisión de Investigación en el Congreso de los Diputados sobre Gescartera. Acuerdo de creación adoptado por el Pleno de la Cámara. Boletín Oficial del Congreso de los Diputados, serie D, General; núm. 225, de 7 de septiembre de 2001, p. 4. En línea: <http://www.congreso.es>.

- Comisión de Investigación en el Senado para determinar las responsabilidades políticas que resulten de la creación, actuación, financiación y encubrimiento de los Grupos Antiterroristas de Liberación (GAL), sin perjuicio de la actuación independiente de los Tribunales de Justicia. Acuerdo de creación adoptado por el Pleno de la Cámara. Boletín Oficial del Senado; serie I, General; núm. 334, de23 de octubre de 1995, p. 1. En línea: <http://www.senado.es>.

- Comisión de Investigación en el Parlamento Vasco al objeto de que examine las responsabilidades políticas surgidas de las irregularidades acontecidas en la provisión de la Oferta Pública de Empleo del Servicio Vasco de Salud-Osakidetza para el ejercicio 1990. Acuerdo de creación adoptado por el Pleno del Parlamento. Boletín Oficial del Parlamento Vasco, núm. 125 Alea, de 25 de marzo de 1994, p. 8664. En línea: <http://parlamento.euskadi.net>.

- Comisión de Investigación en la Asamblea de Madrid para analizar y evaluar las responsabilidades que pudieran derivarse de actuaciones urbanísticas en el ámbito territorial de la Comunidad de Madrid. Acuerdo de creación adoptado por la Mesa de la Diputación Permanente de la Asamblea y la Junta de Portavoces. Boletín Oficial de la Asamblea de Madrid núm. 4, de 18 de julio de 2003, p. 53. En línea: <http:// www.asambleamadrid.es>.

- Comisión de Investigación en las Cortes de Castilla-La Mancha, sobre los hechos acaecidos en el incendio forestal producido en la provincia de Guadalajara. Acuerdo de creación adoptado por el Pleno de las Cortes. Boletín Oficial de las Cortes de Castilla-La Mancha, núm. 103, de 29 de julio de 2005, p. 1. En línea: <http://www.cortesclm.es>.

- Comisión de Investigación en el Parlamento de Navarra sobre el denominado "Caso Otano". Acuerdo de creación adoptado por el Pleno del Parlamento. Boletín Oficial del Parlamento de Navarra, núm. 1, de 5 de enero de 2005, p.6. En línea: <http://www.parlamento-navarra.es>.

- Comisión de Investigación en el Ayuntamiento de Madrid creada por acuerdo del Pleno de 28 de noviembre de 2007 (caso guateque). Acuerdo de creación adoptado por el Pleno del Ayuntamiento. Acuerdos de la sesión plenaria de 28 de noviembre de 2007, p. 1. En línea: <http://www.munimadrid.es>. 
En el caso de los municipios, el quórum exigido para que prospere la creación de una comisión de investigación varía. Por ejemplo, los Reglamento Orgánicos de los Ayuntamientos de Barcelona, Madrid, Castellón de la Plana, Oviedo, San Sebastián y Toledo, exigen una mayoría reforzada al disponer que el acuerdo habrá de adoptarse por mayoría absoluta, mientras que los de los Ayuntamientos de Málaga, Palma de Mallorca, Santa Cruz de Tenerife, Vitoria o Zaragoza, se limitan a decir que el acuerdo se adoptará por mayoría, con lo que bastará pues la mayoría simple.

\section{CONSTITUCIÓN Y ORGANIZACIÓN}

\section{Duración}

La pertenencia de las comisiones de investigación a la categoría de las comisiones especiales, determina que su duración temporal sea limitada, extinguiéndose una vez que haya finalizado la tarea encomendada y, en todo caso, al concluir la legislatura o, tratándose de comisiones municipales, al finalizar el mandato corporativo.

Como hemos visto, la duración de los trabajos indagatorios suele ser uno de los contenidos del acuerdo de creación. No será necesario un nuevo acuerdo para declarar la extinción de la comisión, que se producirá automáticamente una vez que hayan concluido las finalidades que motivaron su creación.

\section{Composición}

Los reglamentos del Congreso y del Senado no disponen nada acerca de la composición de este tipo de comisiones, por lo que deberá ajustarse al precepto general que establece que las comisiones parlamentarias estarán compuestas por los miembros designados por los grupos parlamentarios en proporción numérica a sus representantes en la Cámara. No obstante, en la práctica parlamentaria cabe distinguir a este respecto dos etapas bien diferenciadas: una primera en la que la composición respondía a la regla enunciada de proporcionalidad, y una segunda etapa en la que las comisiones pasan a tener una composición paritaria, integrándose por un miembro, o máximo dos, en representación de cada grupo parlamentario. Esta composición paritaria va acompañada de la previsión -recogida en el acuerdo de creación de la comisión- de que los acuerdos se adopten, entonces, en virtud del criterio del voto ponderado, pues de no ser así el voto de cada miembro de la comisión tendría el mismo valor, lo que iría en contra el principio de representación proporcional exigible en cualquier caso.

El cambio de orientación en la composición de las comisiones de investigación ha tenido que ver con la necesaria flexibilidad con la que deben funcionar este tipo de órganos. Un número excesivo de miembros constreñiría en exceso el trabajo de la comisión y la haría menos operativa, aunque, por otra parte, debe quedar suficientemente garantizada la correlación de fuerzas de las distintas opciones políticas presentes en la cámara. 
La práctica parlamentaria ha quedado positivizada en la última reforma del Reglamento del Congreso que, aunque sigue guardando silencio en relación con la composición, dispone expresamente que "en todo caso, las decisiones de las Comisiones de Investigación se adoptarán en función del criterio de voto ponderado" (artículo 52.3), lo que viene a significar que en estas comisiones la composición no será proporcional en relación a la representación de los distintos grupos en el Pleno -pues en ese caso no tendría sentido el establecimiento del voto ponderado ${ }^{27}-$, sino que será una composición paritaria.

El criterio del voto ponderado para la adopción de decisiones en el seno de las comisiones de investigación se ha incorporado a los reglamentos autonómicos ${ }^{28}$. Además, el de las Cortes de Aragón establece que estarán integradas por un único diputado de cada grupo parlamentario y el de las Cortes de Castilla y León garantiza que todos los grupos contarán como mínimo con un representante.

Por lo que se refiere a los municipios, casi ninguno de los reglamentos orgánicos que regulan las comisiones de investigación alude a su composición ${ }^{29}$, por lo que regirá el principio general de representación proporcional. Los pocos que abordan esta cuestión lo hacen para recoger expresamente dicho principio ${ }^{30}$. Como excepción, el Ayuntamiento de Sevilla sí contiene una referencia expresa, estableciendo que "formarán parte de ellas un concejal de cada uno de los grupos políticos, designados por el Alcalde a propuesta del Portavoz del Grupo" (artículo 115), y que "las decisiones de la comisión se adoptarán mediante votación en la que cada miembro tendrá tantos votos como concejales tenga su grupo en el Pleno" (artículo 117). Esto es, se impone el criterio del voto ponderado, con la significación que ello tiene en el ámbito local y que abordaremos al tratar el modo de adopción de decisiones en el seno de la comisión.

Una de las cuestiones que también se suele plantear en sede parlamentaria es la posibilidad de que en las comisiones de investigación se integren personas que no ostentan la condición de representantes electos. En principio, no hay que olvidar que estas comisiones, por muy especiales que sean, no dejan de ser un órgano parlamentario, por lo que, como tales miembros de un órgano colegiado, con derecho a voz y voto, no podría formar parte de él nadie que no tuviese aquella condición, pues, en definitiva, lo que se está ejerciendo son poderes de las Cámaras. Lo que si cabe es que puedan colaborar con ellas otras personas que, con voz pero sin voto, presten labores de asistencia o asesoramiento técnico ${ }^{31}$.

27 El Reglamento del Parlamento de Galicia, así lo entiende, y en su artículo 50 establece que "los acuerdos, resoluciones o propuestas (de las comisiones de investigación) se adoptarán mediante el voto ponderado, excepto cuando la representación de cada grupo parlamentario en la comisión guarde la proporcionalidad existente en el Pleno".

28 Reglamento del Parlamento de Cataluña (artículo 52) y de la Asamblea de Madrid (artículo 75).

29 Barcelona, Málaga, Madrid, San Sebastián, Vitoria y Zaragoza.

30 Cartagena, Valladolid y Zamora.

31 El Reglamento del Parlamento de Cataluña recoge esta posibilidad cuando dice que "La comisión también pude incorporar especialista, con voz y sin voto, con tareas de asesoramiento técnico, en un número no superior al de diputados miembros de la comisión" (artículo 58). 


\section{Constitución}

Una vez que el Pleno del Ayuntamiento ha adoptado el acuerdo de crear una comisión de investigación, su funcionamiento se acomodará a las disposiciones que con carácter general regulen el del de las demás comisiones, sin perjuicio de las especialidades que pudieran haberse habilitado para aquellas.

A salvo de las disposiciones que los diferentes reglamentos orgánicos municipales hayan podido establecer, de acuerdo con el Reglamento de Organización, Funcionamiento y Régimen Jurídico de las Entidades Locales (ROF), la adscripción concreta a cada comisión de los miembros de la Corporación que deban formar parte de ella en representación de cada grupo, se realizará mediante escrito del portavoz dirigido al Alcalde o Presidente, y del que se dará cuenta al Pleno. Asimismo podrá designarse, de igual forma, un suplente por cada titular (artículo 125.c). Recibidos por el Alcalde los escritos de los portavoces, dictará una resolución nombrando a los miembros de la comisión con su identificación nominal y la especificación de si son titulares o suplentes.

A continuación se procederá a convocar la primera sesión de la comisión que será una sesión constitutiva, por el Alcalde, presidente nato de todas ellas (artículo 125.a) ROF). En la sesión constitutiva, presidida por el Alcalde y actuando como secretario el Secretario General de la Corporación o, en el supuesto de municipios de gran población, por el Secretario General del Pleno, se acordará dicha constitución y en el supuesto de que el Alcalde quiera hacer uso de la facultad que tiene de poder delegar la presidencia en cualquier miembro de la corporación, a propuesta de la propia comisión, se procederá a la elección de dicho Presidente (artículo 125.a) ROF).

\section{Plan de trabajo}

En el ámbito parlamentario, el plan de trabajo es el documento que contiene las diferentes actividades indagatorias que se pretenden llevar a cabo por la comisión y el procedimiento para su consecución. Su elaboración es preceptiva en el Congreso y en el Senado ${ }^{32}$ y en casi la totalidad de los parlamentos autonómicos. Sin embargo, los reglamentos orgánicos municipales, salvo alguna excepción ${ }^{33}$, no aluden a este instrumento que, en la práctica, constituye una importante ayuda para la planificación del funcionamiento de un órgano que tiene que realizar en un tiempo relativamente breve toda una serie de actuaciones que es preciso organizar.

32 El Reglamento del Congreso establece únicamente que "las Comisiones de Investigación elaborarán un plan de trabajo" (artículo 52), mientras que el Reglamento del Senado, más explícito, señala que "Una vez constituidas estas Comisiones elaborarán un plan de trabajo fijando sus actuaciones y plazos" (artículo 59).

33 Los reglamentos orgánicos de los Ayuntamientos de Móstoles, Santa Cruz de Tenerife y Valladolid, sí prevén que las comisiones de investigaciones establezcan un programa de trabajo para la realización del cometido encomendado. 
Su contenido alude a las vías y procedimientos a través de los cuales el órgano de encuesta obtendrá los conocimientos necesarios para formarse un juicio sobre los hechos objeto de la investigación, es decir, los documentos que se van a solicitar, la lista de las personas cuya comparecencia se va a requerir, los expertos cuya declaración como peritos sea relevante para el conocimiento de la materia, etc.

En la práctica parlamentaria la elaboración del plan de trabajo se inicia en la sesión constitutiva de la comisión, a partir de las propuestas que formulan sus miembros sobre solicitudes de información y comparecencias. Tiene un carácter abierto, de tal forma que puede ir adaptándose a las necesidades que puedan surgir como consecuencia de las actuaciones indagatorias ${ }^{34}$. La aprobación del plan, en buena lógica, corresponde a la propia comisión.

\section{Adopción de acuerdos}

La forma de adopción de las decisiones en el seno de las comisiones de investigación parlamentarias ha ido unida a la evolución que ha experimentado su composición, pues, el paso de una composición proporcional a una composición paritaria ha determinado que los acuerdos se adopten en virtud del criterio del voto ponderado.

El sistema de voto ponderado significa que el voto de un diputado, propuesto por su grupo parlamentario para formar parte de una comisión, es igual al número de diputados que tiene el grupo parlamentario al que representa. La diferencia entre un voto por mayoría y un voto ponderado radica, pues, en que en el voto por mayoría cada votante tiene un voto, mientras que en el voto ponderado se asigna un valor determinado al voto de un votante en función de la representación que tenga el grupo político al que pertenece, por lo que el voto de cada votante no tiene el mismo valor.

La asimilación de este criterio por parte de las comisiones de investigación que puedan crearse en los Ayuntamientos, plantea la cuestión de su admisión a la vista de la doctrina jurisprudencial que ha rechazado esta forma de votación para las comisiones informativas y las comisiones especiales. Las sentencias que abordan esta cuestión consideran que el establecimiento del voto ponderado en las comisiones municipales desborda la potestad de autoorganización de los Ayuntamientos y remiten a la doctrina del Tribunal Constitucional que, en sentencias de 25 de enero de 1993 y 6 de marzo de 1985, ha defendido la necesaria composición proporcional de estos órganos frente a una posible composición paritaria de los mismos.

34 Según lo manifestado por los Servicios Jurídicos del Congreso, acerca del contenido del plan de trabajo "parece claro que deben inscribirse en él la totalidad de las actuaciones que la comisión acuerde o haya acordado realizar, con la mención de las circunstancias de lugar, tiempo y forma de su realización, sin perjuicio de la posible revisión ulterior del plan a la vista del desarrollo de las propias actuaciones". Revista de las Cortes Generales (1998), núm. 14, p. 131. 
En efecto, la jurisprudencia reseñada entiende que una composición no proporcional de las comisiones municipales resulta constitucionalmente inaceptable al tratarse de divisiones internas del Pleno que, en cuanto partes del mismo, deben reproducir, en lo posible, la estructura política de éste, pues, de otro modo, se hurtaría a los concejales de la participación en una parte importante de los procesos de decisión.

En concreto, la sentencia del Tribunal Supremo de 8 de febrero de 1999, haciéndose eco de otra de 28 de noviembre de 1995, señala que "el establecimiento del voto ponderado en dichas Comisiones (...) perjudica el estatuto individual de los concejales, además de al principio de proporcionalidad (...) pues si bien es cierto que los acuerdos municipales que establecen el voto ponderado, posiblemente permitirían alcanzar dicha proporcionalidad, ello sería sólo en el aspecto funcional de la adopción de los acuerdos por parte de las comisiones, pero no en su estructura o composición".

\section{Publicidad}

El carácter público o secreto de las sesiones de las comisiones de investigación es uno de sus aspectos más controvertidos, existiendo razonamientos a favor y en contra. A favor se argumenta que la discusión parlamentaria debe conocerse y someterse a la observación crítica de los ciudadanos, lo que se consigue a través de la publicidad de los trabajos de la comisión. En contra, se alude al especial cuidado con que deben tratarse determinadas materias o la necesidad de proteger los derechos fundamentales de las personas relacionadas con la investigación.

En nuestro derecho, los reglamentos parlamentarios, especialmente el del Congreso, imponían el carácter secreto de las sesiones de las comisiones de investigación. La reforma del citado reglamento, en 1994, modificó este principio introduciendo como regla general de su funcionamiento el principio de publicidad ${ }^{35}$.

El alcance de este principio se recoge en el artículo 64 del Reglamento que establece que las sesiones de las comisiones no son públicas aunque sí pueden asistir los representantes debidamente acreditados de los medios de comunicación social, excepto cuando tengan carácter secreto. En este punto, hay que precisar la distinción entre los conceptos de sesiones secretas y sesiones públicas. El que las comisiones parlamentarias, con carácter general, no sean públicas implica que no pueden asistir a ellas quienes no estén autorizados, pero sí los medios de comunicación social debidamente acreditados. Pero el que no sean públicas no quiere decir que sean secretas,

35 Mientras las comisiones de investigación funcionaron en secreto, el conocimiento oficial de lo llevado a cabo tenía lugar únicamente través de la publicación de las conclusiones aprobadas por el Pleno y el extraoficial a través de las filtraciones que de las actuaciones de la comisión se hacían a los medios de comunicación, lo que, entre otros motivos, justificó la reforma del reglamento en este aspecto. 
pues sí pueden asistir los medios de comunicación, mientras que en las secretas ni siquiera estos pueden estar presentes.

Según el citado artículo 64, las sesiones de las comisiones, incluidas las de investigación, serán secretas cuando lo acuerden sus miembros por mayoría absoluta. También serán secretas las sesiones de las comisiones de investigación preparatorias de su plan de trabajo o de las decisiones del Pleno, las de deliberación interna, o las reuniones de las ponencias. Serán secretos, asimismo, los informes o documentos facilitados a estas comisiones para el cumplimiento de sus funciones, cuando lo disponga una ley o cuando así lo acuerde la propia Comisión. Por el contrario, a las sesiones en las que se celebren comparecencias informativas, sí podrán asistir los medios de comunicación, salvo cuando la comparecencia verse sobre materias declaradas reservadas o secretas, conforme a la legislación vigente, o cuando a juicio de la Comisión los asuntos a tratar coincidan con actuaciones judiciales que hayan sido declaradas secretas.

La publicidad afecta también la documentación formal de las sesiones. Según el Reglamento del Congreso (artículo 96), en el Diario de Sesiones se reproducen las intervenciones y acuerdos adoptados en las comisiones siempre que no tengan carácter secreto, pues de las sesiones secretas se levanta acta taquigráfica, cuyo único ejemplar se custodia en la Presidencia, donde puede ser consultado por los Diputados previo acuerdo de la Mesa. Por otra parte, los acuerdos adoptados se publicarán en el Diario de Sesiones, salvo que la Mesa de la Cámara decida su carácter reservado.

En definitiva, tras la reforma reglamentaria se ha establecido con carácter general el carácter no público de las sesiones de las comisiones, lo que implica que, si bien no están abiertas al público, ello no impide que los ciudadanos puedan conocer lo que allí sucede, bien por los medios de comunicación social acreditados, que sí pueden estar presentes, o bien por los diarios de sesiones en que se reproducen íntegramente todas las intervenciones y acuerdos adoptados. Queda así garantizado el principio de publicidad de las actuaciones de la comisión a pesar de la no asistencia de público La distinción entre sesiones públicas y no públicas, basado en la presencia o no del público, respectivamente, carece, por tanto, de sentido, siendo la distinción efectiva la que diferencia entre sesiones con publicidad y sesiones secretas, a las que no asiste el público ni los medios de comunicación ni se reflejan en las publicaciones de las Cámaras ${ }^{36}$.

Una regulación semejante a la vigente para el Congreso es la que se recoge por la mitad, aproximadamente, de los reglamentos de los parlamentos autonómicos. La otra mitad se decanta por determinar, en todo caso o con alguna matización, el carácter secreto de las sesiones y trabajos de las comisiones de investigación ${ }^{37}$.

36 Alonso de Antonio (1990), “El deber de secreto de los parlamentarios”. Revista de la Facultad de Derecho de la Universidad Complutense, núm. 76, p. 9.

37 El secreto se declara en todo caso en las Cortes de Aragón, en el Parlamento de las Islas Baleares, las Cortes de Castilla y León, la Asamblea Regional de Murcia y el Parlamento Vasco. La Junta General del Prin- 
En el caso de los Ayuntamientos, la Ley Reguladora de las Bases del Régimen Local establece el carácter público de las sesiones del Pleno, aunque pueden ser secretos el debate y votación de aquellos asuntos que puedan afectar al derecho fundamental al honor, a la intimidad personal y familiar y a la propia imagen, así como cuando se acuerde por mayoría absoluta (artículo 70). Por el contrario, no serán públicas las sesiones de la Junta de Gobierno Local (artículo 70 LRBRL) y las de las Comisiones Informativas (artículo 227.2 ROF).

Respecto de las comisiones, algunos Ayuntamientos como Madrid, Barcelona, Málaga o Bilbao, haciendo uso de su potestad de autoorganización han determinado en sus reglamentos orgánicos el carácter público de las sesiones de estos órganos, con alguna matización ${ }^{38}$, de tal forma que se admite la presencia de público, y no únicamente de medios de comunicación. Algunos otros ayuntamientos, sin embargo, como es el caso de Palma de Mallorca o Zaragoza, recogen en sus reglamentos, específicamente para las sesiones de las comisiones de investigación, su carácter no público.

Así pues, en el ámbito municipal el carácter público o secreto de las sesiones de una comisión de investigación dependerá de si existe alguna previsión al respecto en las correspondientes normas orgánicas, para las sesiones de las comisiones en general o para las de investigación en particular. En su defecto, podría aplicarse, por analogía, lo dispuesto en el ROF para las comisiones informativas, en el sentido de considerar que sus sesiones no son públicas. Sin perjuicio de que, aún admitiéndose reglamentariamente el acceso del público a las sesiones, éste pueda quedar restringido cuando en una sesión concurrieren los supuestos que se enumeran para declarar secreto el debate y votación en sede plenaria: que así se acuerde por mayoría absoluta o que se trate de asuntos que puedan afectar al derecho al honor, a la intimidad personal y familiar y a la propia imagen.

\section{INSTRUMENTOS DE LA INVESTIGACIÓN}

Para el cumplimiento de sus objetivos las comisiones de investigación parlamentarias tienen que recabar información sobre el asunto investigado hasta conseguir el conocimiento imprescindible que les permitir emitir un juicio valorativo ${ }^{39}$. La obtención de información, escrita y verbal, se canaliza por dos vías, que se enmarcan en la

cipado de Asturias dispone el secreto únicamente "si así se acuerda por el Pleno al constituirlas"; en la Asamblea de Madrid son secretas las sesiones salvo aquellas en las que se efectúen comparecencias, y en las Cortes de Castilla la Mancha se permite el carácter público por acuerdo de la Mesa oída la Junta de Portavoces.

38 Por ejemplo, el Reglamento Orgánico del Pleno del Ayuntamiento de Bilbao, establece que "Las sesiones de las Comisiones podrán ser públicas o carecer de este carácter, en función de lo que se determine en el acuerdo plenario de su constitución o, en su caso, modificación. En el ejercicio de las funciones resolutorias que el Pleno les delegue procederá su carácter público. No obstante, podrán ser secretos el debate y la votación de aquellos asuntos que puedan afectar a los Derechos Fundamentales de la ciudadanía, cuando así se acuerde por mayoría absoluta."

39 El Tribunal Constitucional, en su sentencia 161/1988, de 20 de septiembre, al abordar la función de información parlamentaria, ha considerado que el sentido propio de tal derecho funcional se encuentra 110 tiene un alcance claramente instrumental. 
ejecución de su plan de trabajo, a saber: las solicitudes de información escrita y de documentación, y las comparecencias.

Las facultades específicas que el ordenamiento jurídico les otorga para el ejercicio de su actividad indagatoria a través de los procedimientos enunciados, se encuentran en las siguientes disposiciones:

- La propia Constitución, que en su artículo 76 las habilita para requerir la comparecencia de ciudadanos ante ellas, y en el artículo 109 para que, dentro de las facultades generales que se atribuyen a las Cortes Generales, puedan recabar información del Gobierno y de cualquier autoridad del Estado y de las Comunidades Autónomas.

- La Ley Orgánica 5/1984, de 24 de mayo, de comparecencias ante las Comisiones de Investigación del Congreso y del Senado, que regula lo relativo a la adquisición de información sobre funcionarios, autoridades y ciudadanos en general.

- El Decreto Ley 5/1994, de 29 de abril, que regula la obligación de comunicación de determinados datos -tributarios y financieros- a requerimiento de las comisiones parlamentarias de investigación.

Este marco jurídico se completa con los preceptos de los reglamentos de las Cámaras.

Puesto que ninguna de las normas citadas resulta de aplicación a las comisiones de investigación municipales, pues su ámbito se restringe a las actuaciones indagatorias realizadas por las que se crean en los órganos parlamentarios del Estado-Congreso y Senado o ambas cámaras-, tanto la obtención de información como las comparecencias deberán ajustarse a las disposiciones reguladoras del régimen local que resulten de aplicación y a las que, en su caso, hayan podido recoger los respectivos reglamentos orgánicos.

\section{Obtención de información escrita y documentación}

Uno de los específicos poderes atribuidos a las órganos de investigación, a efectos de que puedan desarrollar las funciones para las que han sido creados, es el que se conoce con el anglicismo the power to send for papers and records, que podría traducirse como la facultad para requerir documentos y archivos.

Es evidente que la actividad de una comisión de investigación depende de la posibilidad que tenga de disponer de toda la documentación precisa para el cumplimiento de sus objetivos, y que debe de estar a disposición de los miembros de la comisión antes de que se celebren las comparecencias para que éstas resulten operativas. 
Esta facultad de solicitar información documental se halla regulada en el ámbito parlamentario de forma común para todas las comisiones, sin que las de investigación tengan una normativa específica al respecto. Les será de aplicación, por tanto, las reglas generales que se concretan, en primer lugar, en el artículo 109 de la CE que establece que "Las Cámaras y sus Comisiones, podrán recabar, a través de los Presidentes de aquéllas, la información y ayuda que precisen del Gobierno y de sus Departamentos y de cualesquiera autoridades del Estado y de las Comunidades Autónomas", y, en segundo lugar, en los reglamentos parlamentarios que, en general, suelen reproducir el precepto constitucional. Tal es el caso del Reglamento del Congreso, que en el apartado 1 de su artículo 44, señala que las comisiones, por conducto del Presidente del Congreso, podrán recabar la información y la documentación que precisen del Gobierno y de las Administraciones Públicas.

Por su parte, la normativa establecida en los reglamentos de los parlamentos autonómicos es similar a la del Reglamento del Congreso, no existiendo tampoco referencias específicas para las comisiones de investigación.

A diferencia de lo que ocurre con las comparecencias, como veremos al hablar de ellas, la solicitud de información por parte de las comisiones de investigación no está protegida por vía del artículo 76 CE -y la Ley Orgánica que lo desarrolla-, por lo que esta facultad no está garantizada con una sanción en caso de desatender a lo solicitado. Las normas citadas contienen únicamente una facultad de conseguir información, sin que las comisiones tengan la posibilidad de imponer jurídicamente su obtención, aunque tanto el Gobierno como la Administración sólo pueden invocar frente a las comisiones de investigación razones fundadas en la necesidad de tutelar derechos o bienes constitucionales y tales razones han de ser jurídicas y no ampararse en criterios meramente de valoración política ${ }^{40}$.

El ámbito material de la información que se puede recabar es muy amplio, de tal forma que se podría solicitar toda la documentación que se considerase necesaria y significativa, con dos únicas limitaciones: la petición no podría versar sobre materias afectadas por la legislación de secretos oficiales y no podría accederse a información que pudiera afectar a los derechos fundamentales de las personas.

Asimismo, siguiendo a Lavilla Rubira ${ }^{41}$, el alcance de la información tiene los siguientes límites positivos: En primer lugar, la expresión información ha sido interpretada en la práctica parlamentaria en el sentido de que el destinatario de la solicitud no está obligado a elaborar el informe o el documento requerido, sino que ha de obrar previamente en su poder, de ahí que puedan no tramitarse la solicitudes de informes o documentos que todavía no existen o se encuentran en proceso de elaboración y la

40 Marcos Francisco Massó Garrote (2001); Poderes y límites de la investigación parlamentaria en el Derecho Constitucional español. Madrid. Monografías del Congreso de los Diputados, p. 69.

41 J.J. Lavilla Rubira (1991), Congreso de los Diputados y demás poderes públicos: información, con-

112 trol y responsabilidad. Estudios sobre la Constitución Española. Civitas,. p. 2015. 
imposibilidad de que se requieran de forma periódica documentos a medida que se vayan elaborando. En segundo lugar, el término documento debe entenderse en el sentido maximalista de la Ley de Patrimonio Histórico Español, según el cual documento es “toda expresión en lenguaje natural o convencional y cualquier otra expresión gráfica, sonora o en imagen, recogidas en cualquier tipo de soporte material, incluso soportes informáticos". En último lugar, la potestad de recabar información no debería amparar la solicitud de remisión de documentación que, aún obrando en poder de la administración, sea ajena a la actividad sustantiva de la comisión de investigación.

La normativa en esta materia se completa con el antes citado Real Decreto-Ley 5/1994, de 29 de abril, que establece la obligación de la Administración tributaria y entidades financieras de remitir a las comisiones de investigación la información que se les solicite siempre que se refieran a personas que desempeñen o hubieran desempeñado, por elección o por nombramiento, determinados puestos de carácter público y se cumplan determinadas condiciones ${ }^{42}$. La norma se refiere únicamente a las comisiones de investigación de las Cortes Generales dejando a las de los parlamentos autonómicos en una situación de desapoderamiento respecto de esta información.

Lo mismo ocurre respecto de las entidades locales a las que no alcanzan ninguna de las disposiciones normativas a las que se ha hecho referencia y que tampoco gozan de ningún precepto que con carácter general las habilite para requerir documentación a otras instancias administrativas.

La facultad informativa se reconoce en el régimen local a los concejales miembros de la corporación a título individual y circunscrito al ámbito municipal. Es el artículo 77 de la Ley Reguladora de las Bases del Régimen Local el que configura como un derecho de todos los miembros de la Corporación el obtener del Alcalde o de la Junta de Gobierno cuantos antecedentes, datos o informaciones obren en poder de los servicios de la Corporación y resulten precisos para el desarrollo de su función y a que la solicitud de ejercicio de tal derecho sea resuelta motivadamente en los cinco días naturales siguientes a aquel en que se hubiese presentado.

42 El artículo único de este Real Decreto-Ley, dispone que:

"La Administración Tributaria y las entidades de crédito, entidades aseguradoras, sociedades o agencias de valores, sociedades gestoras de instituciones de inversión colectiva, establecimientos financieros de crédito y, en general, cualesquiera entidades financieras, deberán proporcionar cuantos datos, informes, antecedentes o documentos les sean requeridos por las Comisiones Parlamentarias de Investigación a que se refiere el artículo 76 de la Constitución siempre que concurran las condiciones siguientes:

a) Que se refieran a personas que desempeñen o hubieren desempeñado, por elección o nombramiento, su actividad como altos cargos o equivalentes en todas las Administraciones Públicas, sus organismos autónomos, entidades de Derecho Público y Presidentes y Directores ejecutivos o equivalentes de los organismos y empresas de ellas dependientes y de las sociedades mercantiles en las que sea mayoritaria la participación directa o indirecta de las Administraciones Públicas o de las restantes entidades de Derecho Público o estén vinculadas a las mismas por constituir con ellas una unidad de decisión.

b) Que el objeto de la investigación tenga relación con el desempeño de aquellos cargos.

c) Que dichas Comisiones entendieran que sin tales datos, informes, antecedentes o documentos no sería posible cumplir la función para la que fueron creadas". 
Este derecho, que forma parte del régimen estatutario de los concejales, se desarrolla en el ROF en los artículos 14, 15 y 16 y, de manera más o menos similar, en los distintos reglamentos orgánicos municipales.

La diferencia con el ámbito parlamentario estriba, por tanto, en que mientras que en él existe el reconocimiento de una potestad a favor de las comisiones parlamentarias como órganos colegiados de las cámaras para dirigirse a los poderes públicos en busca de información, en el ámbito local lo que hay es un reconocimiento individual a los concejales de un derecho de acceso a la información municipal para el mejor cumplimiento de sus funciones, similar al que también se reconoce a los diputados $^{43}$, aunque en el caso de los concejales, como se ha dicho, circunscrito a la documentación en poder de la corporación.

No obstante, si se concibe este derecho como un instrumento más de los que se ponen a disposición de los concejales para el seguimiento y control de la acción del ejecutivo municipal ${ }^{44}$, aunque su ejercicio se reconozca de manera individualizada, nada parece, en principio, impedir que una comisión de investigación integrada por concejales pudiera ejercer tal facultad en ejercicio, asimismo, de sus funciones de control y fiscalización, si bien, como reiteradamente se ha indicado, limitada a la información existente en el propio Ayuntamiento.

Más allá de este límite, la petición de documentación a otras administraciones podría encontrar amparo en el marco de las relaciones interadministrativas de la Ley de las Bases del Régimen Local. Concretamente, el artículo 55 de dicha Ley determina que para la efectividad de la coordinación y eficacia administrativas, las Administraciones del Estado y de las Comunidades Autónomas, de un lado, y las entidades locales, de otro, deberán en sus relaciones recíprocas, entre otras cuestiones, facilitarse información sobre la propia gestión que sea relevante para el adecuado desarrollo de sus cometidos. Sobre la base de este principio de colaboración, una comisión de investigación municipal podría dirigirse por conducto del Presidente de la Corporación, a quién le corresponde la representación de la institución, a otras administraciones, no con una intención fiscalizadora, sino para solicitarles su colaboración en el caso de que en el curso de una investigación se considere conveniente dirigirse a ellas en busca de información para el correcto desarrollo de sus trabajos.

43 El Reglamento del Congreso reconoce a los diputados, individualmente considerados, previo conocimiento del respectivo grupo parlamentario, el derecho para recabar de las administraciones públicas los datos, informes o documentos que obren en poder de éstas y que deben facilitar en un plazo no superior a treinta días o bien manifestar a su Presidente "las razones fundadas en derecho" que impidan entregar la documentación solicitada (artículo 7).

44 La STS de 9 de diciembre de 1995, considera que "una información adecuada es presupuesto ineludible (... ) para una correcta labor de control y fiscalización”, y la de 25 de junio de 1999, que los concejales tienen "el derecho a la fiscalización de las actuaciones municipales y al control, análisis y estudio e 114 información de los antecedentes necesarios, obrantes en los servicios municipales, 
En esta línea, y a título de ejemplo, el Reglamento Orgánico del Ayuntamiento de Sevilla, al regular las comisiones de investigación, les atribuye la facultad de "recabar cuanta documentación e informes convengan a su fin específico, y requerir a otras Administraciones para que colaboren en la investigación, con los datos que obren a su poder" (artículo 116.1). A renglón seguido, reconoce que "cualquiera de los miembros podrá recabar de los servicios municipales los antecedentes y documentos necesarios para esclarecer los hechos objeto de la investigación" (artículo 116.2).

\section{Comparecencias}

\subsection{Obligación de comparecer}

La convocatoria de personas para que declaren ante las comisiones parlamentarias de investigación, con el fin de que puedan aportar información para el esclarecimiento de los hechos, constituye una de las facultades más llamativas de éstos órganos y prueba de su trascendencia es que se recoge en la propia Constitución como un deber que corresponde a quienes sean requeridos por las Cámaras para comparecer ante ellas ${ }^{45}$. Este deber se desarrolla por la Ley Orgánica 5/1984, de 29 de mayo, que fija el marco de garantías para su cumplimiento ${ }^{46}$ y se completa por el Código Penal al sancionar su inobservancia tipificándola como un delito de desobediencia ${ }^{47}$.

45 El artículo 76.2 de la CE establece que: "Será obligatorio comparecer a requerimiento de las Cámaras. La Ley regulará las sanciones que puedan imponerse por incumplimiento de esta obligación”.

46 El artículo 1.1 de la Ley Orgánica 5/1984, en una interpretación amplia del artículo 76.2 de la Constitución, establece que el deber constitucional de comparecer afecta a los particulares, sean españoles o extranjeros residentes en el país, y a toda clase de funcionarios y autoridades, los cuales están obligados a comparecer personalmente para informar, a requerimiento de las Comisiones de Investigación nombradas por las Cámaras Legislativas.

Asimismo, la Ley otorga un tratamiento especial a las personas jurídicas, pues determina que el requerimiento para comparecer se entenderá dirigido a sus representantes legales, los cuales pueden comparecer acompañados, a efectos de asesoramiento, de las personas que designe el órgano social de administración correspondiente (artículo 2.3).

También son objeto de un tratamiento particularizado los funcionarios públicos, los cuales no precisan autorización de sus superiores para declarar, pues, aunque se exige que a éstos se les envíe copia de la citación, tal remisión lo es únicamente a efectos de su conocimiento (artículo 2.4).

47 La obstaculización a la investigación de Comisiones y órganos de investigación, aparece regulada en el artículo 502 del Código Penal, en los siguientes términos:

“1. Los que, habiendo sido requeridos en forma legal y bajo apercibimiento, dejaren de comparecer ante una Comisión de investigación de las Cortes Generales o de una Asamblea Legislativa de Comunidad Autónoma, serán castigados como reos del delito de desobediencia. Si el reo fuera autoridad o funcionario público, se le impondrá además la pena de suspensión de empleo o cargo público por tiempo de seis meses a dos años.

2. En las mismas penas incurrirá la autoridad o funcionario que obstaculizare la investigación del Defensor del Pueblo, Tribunal de Cuentas u órganos equivalentes de las Comunidades Autónomas, negándose o dilatando indebidamente el envío de los informes que éstos solicitaren o dificultando su acceso a los expedientes o documentación administrativa necesaria para tal investigación.

3. El que convocado ante una Comisión parlamentaria de investigación faltare a la verdad en su testimonio, será castigado con la pena de prisión de seis meses a un año o multa de seis a doce meses." 
Por su parte, los Reglamentos parlamentarios regulan la comparecencia de los ciudadanos ante las comisiones de investigación de acuerdo con lo dispuesto en la antes citada Ley Orgánica ${ }^{48}$.

En este contexto, se cuestiona el alcance que tal facultad puede tener en el ámbito municipal, pues la obligación constitucional de comparecer se predica únicamente de las cámaras estatales, y el Código Penal sanciona únicamente a quienes dejaren de comparecer ante una comisión de investigación de las Cortes Generales o de una Asamblea Legislativa de Comunidad Autónoma, sin que se refiera en absoluto a los Plenos municipales.

Precisamente, el hecho de no contar con una disposición expresa que sancione la incomparecencia de los requeridos constituye el punto débil de las comisiones de investigación de los ayuntamientos, que se encuentran con que la negativa a comparecer no tiene consecuencias penales, lo que las coloca en una situación pareja a la de las Comunidades Autónomas antes de la reforma del artículo 502 del Código Penal, en un escenario de total parálisis en el que resulta imposible obtener resultado alguno si los convocados a comparecer se niegan a ello.

A pesar de que algunos reglamentos orgánicos municipales recogen la posibilidad de instar a comparecer ante las comisiones de investigación a personas que puedan tener relación con el asunto que se esté investigando o cuyo testimonio se estime conveniente ${ }^{49}$, la ausencia de una norma de cobertura para una posible coerción implica que esos requerimientos no dejan de ser sino meras invitaciones para que los destinatarios asistan sólo si así lo estiman oportuno, con la posibilidad de rechazarlas sin que ello les suponga responsabilidad alguna. Estas comisiones, por tanto, no pueden exigir a nadie comparecer so pena de castigar tal conducta como un hecho punible, pues carecen de un poder efectivo para compeler a su cumplimiento ${ }^{50}$.

No obstante, puede darse el caso de que los reglamentos orgánicos incluyan como uno de los medios de control sobre el ejecutivo las comparecencias, ante el

48 El Reglamento del Congreso de los Diputados establece respecto de las comparecencias lo siguiente (artículo 52):

“2. Las Comisiones de Investigación elaborarán un plan de trabajo y podrán nombrar Ponencias en su seno y requerir la presencia, por conducto de la Presidencia del Congreso, de cualquier persona para ser oída.

Tales comparecencias se ajustarán a lo dispuesto en la Ley prevista en el artículo 76.2 de la Constitución y responderán, en todo caso, a los siguientes requisitos:

a) La notificación del requerimiento para comparecer y de los extremos sobre los que se deba informar habrá de hacerse con quince días de antelación, salvo cuando, por concurrir circunstancias de urgente necesidad, se haga con un plazo menor, que en ningún caso será inferior a tres días.

b) En la notificación, el ciudadano requerido será advertido de sus derechos y obligaciones y podrá comparecer acompañado de la persona que designe para asistirlo".

49 Reglamentos Orgánicos de los Ayuntamientos de Móstoles (artículo 185.3); Santa Cruz de Tenerife (artículo 25.2); Sevilla (artículo 116.1); Valladolid (artículo 52.3) y Vitoria (artículo 156.2).

50 En esta línea, el Reglamento Orgánico del Pleno del Ayuntamiento de Vitoria, establece que "La 116 será voluntaria". 
Pleno o sus comisiones, de miembros del gobierno municipal, directivos o funcionarios de la corporación. En ese caso, su asistencia para que aporten a una comisión de investigación información sobre los asuntos que conozcan por razón de su cargo o de su trabajo, deberá recibir el mismo tratamiento que el previsto con carácter general para su comparecencia ante los citados órganos ${ }^{51}$.

\subsection{Obligación de declarar}

En el ámbito parlamentario, sentada la obligación de comparecer, se han suscitado dudas sobre si ese deber de comparecer incluye el deber de declarar. En este sentido, parece que el análisis más certero es el que considera que el deber de declarar está implícito en el de comparecer y que deriva, tanto del tenor literal de la Ley Orgánica 5/1984, "están obligados a comparecer personalmente para informar" (artículo 1.1), como de la propia naturaleza del acto, en cuanto que la comparecencia es un acto finalista, es decir, está regulado en función de obtener una finalidad concreta que es la información del requerido ${ }^{52}$.

Sin embargo, es también evidente que entran en juego los derechos constitucionales que amparan al declarante y que operan como límite a la comparecencia. Entre los derechos susceptibles de ser reivindicados en este ámbito destaca, en primer lugar, el de no declarar sobre su ideología, religión o creencias (artículo 16.2 CE), ni a desvelar su intimidad (artículo 18 CE).

Asimismo, es posible alegar en esta sede el derecho de guardar silencio cuando el compareciente considere que con su declaración pudiera estar inculpándose de un hecho constitutivo de un delito susceptible de ser puesto en conocimiento del Ministerio Fiscal. El derecho a guardar silencio puede ser planteado, pues, en el caso de que el compareciente invoque su voluntad a no declarar o no hacerlo contra sí mismo, lo cual plantearía la operabilidad de la garantía procesal del artículo 24.2 CE en el ámbito de las comisiones parlamentarias de investigación, en cuanto un derecho subjetivo de la persona que le acompaña en todas sus actuaciones ${ }^{53}$. Tal sería la situación del imputado en un procedimiento penal que es convocado ante una comisión para deponer sobre los mismos hechos, en la que habría que reconocerle la posibilidad de callar ejerciendo su elemental derecho a la defensa y sin que por ello sea posible incriminarle ${ }^{54}$.

51 El Reglamento Orgánico del Ayuntamiento de Sevilla, prevé, específicamente, que se podrá requerir la comparecencia de concejales y funcionarios para que expliquen los hechos que han realizado, producido o conocido, así como que los requeridos deberán atender las peticiones de comparecencia y contestar a las preguntas que se les hagan, salvo que de sus respuestas pudiera resultar la propia responsabilidad (artículo 116.3).

52 Alfonso Arévalo Gutiérrez (1987), "Reflexiones sobre las comisiones de investigación o encuestas parlamentarias en el ordenamiento constitucional español”, Revista de las Cortes Generales, núm. 11, p. 183.

53 María Torres Bonet; Op. cit., pp. 333-335.

54 Ignacio Torres Muro; Op. cit., p. 109. 


\subsection{Derechos de los comparecientes}

\subsubsection{Al respeto de los derechos fundamentales}

La comparecencia de personas ante las comisiones de investigación puede suponer una limitación al desarrollo de los derechos fundamentales, siendo los más fácilmente susceptibles de ser afectados los que se encuentran expresamente previstos en la propia Ley Orgánica 5/1984: intimidad, honor, secreto profesional y cláusula de conciencia.

Como medida de protección, la propia Ley contiene un mandato a las Mesas de las Cámaras para que velen por la salvaguarda de esos derechos ante las Comisiones de Investigación (artículo 1.2).

\subsubsection{A la convocatoria en tiempo y forma}

Los requeridos a comparecer tienen derecho a que el requerimiento les sea formulado con la antelación prevista y con la observancia de las disposiciones de la Ley Orgánica 5/1984. El incumplimiento de estas disposiciones conllevará como consecuencia la imposibilidad de imponer sanciones penales en caso de incomparecencia.

\subsubsection{A comparecer asistido por otra persona}

La Ley Orgánica 5/1984 establece que, “previa conformidad del Presidente de la Comisión, el ciudadano requerido podrá comparecer acompañado de la persona que designe para asistirlo" (artículo 3.1).

Este derecho a comparecer asistido, se entiende por la doctrina que es un derecho a la defensa sui generis, que permitiría al compareciente tener los auxilios necesarios a la hora de responder a las cuestiones que se le planteen.

Se interpreta, pues, como la posibilidad de comparecer con asistencia letrada o de otro tipo ${ }^{55}$, pues ni la ley ni los reglamentos parlamentarios ofrecen mayores precisiones al respecto. Algún autor entiende que la asistencia letrada es especialmente aconsejable cuando en las investigaciones se abordan actividades o hechos presuntamente delictivos ${ }^{56}$. La posibilidad de comparecer en compañía de un abogado ofrece al compareciente una garantía similar a la que correspondería al detenido. Parece

55 Alfonso Arévalo Gutiérrez (1987); “Reflexiones sobre las comisiones de investigación o encuestas parlamentarias en el ordenamiento constitucional español”; Revista de las Cortes Generales, núm. 11, p. 188, y Rosario García Mahamut (1996). Las Comisiones parlamentarias de investigación en el Derecho Constitucional español. Madrid. McGraw-Hill, pp. 239-245.

56 María Torres Bonet; Op. cit., pp. 322-326. 
conveniente que tenga tal derecho en un procedimiento que, aún sin tener naturaleza jurisdiccional, puede reportar consecuencias judiciales para el declarante, pues si la comisión entendiese que de sus manifestaciones se dedujeran indicios racionales de criminalidad, deberá notificarlo a la Mesa de la Cámara para que ésta, a través de la Presidencia, lo pusiera en conocimiento del Ministerio Fiscal.

Por lo que se refiere a las condiciones de ejercicio de este derecho, según la citada Ley Orgánica, la comparecencia en compañía de un asistente se condiciona a la previa conformidad del Presidente de la Comisión, con lo cual, la garantía que ofrece la Ley puede quedar sin efecto en el caso de que aquél no permitiera la asistencia. Quizás por este motivo, la nueva redacción del artículo 52.2. del Reglamento del Congreso ${ }^{57}$ configura la presencia de un asistente como un derecho del compareciente, ya que en esta norma, a diferencia de la Ley Orgánica, no se menciona la autorización del Presidente de la Comisión.

\subsubsection{Al reembolso de los gastos ocasionados}

La Ley Orgánica 5/1984, establece que los gastos desembolsados por los comparecientes como consecuencia del requerimiento de comparecencia les serán abonados con cargo al presupuesto de la Cámara respectiva, una vez hayan sido debidamente justificados (artículo 5).

\subsection{Procedimiento de la comparecencia}

\subsubsection{El requerimiento}

Tanto la Ley Orgánica 5/1984, como el Reglamento del Congreso y gran parte de los de los parlamentos autonómicos se refieren a los requerimientos de comparecencia ${ }^{58}$.

57 Reforma de 16 de junio de 1994.

58 El artículo 2 de la Ley Orgánica 5/1984, dispone al respecto que:

“1. Los requerimientos para comparecer se formularán mediante citación fehaciente de la Presidencia de la Cámara respectiva o del Presidente del Congreso en el caso de las Comisiones Mixtas de Investigación del Congreso y del Senado, en los términos establecidos en los Reglamentos del Congreso de los Diputados y del Senado, y en forma de oficio, en el que se hará constar:

a) La fecha del acuerdo en virtud del cual se requiere y la Comisión de Investigación ante la que se ha de comparecer.

b) El nombre y los apellidos del requerido y las señas de su domicilio.

c) El lugar, el día y la hora en que haya de comparecer el requerido, con apercibimiento de las responsabilidades en que pudiera incurrir en caso de desobediencia.

d) El tema sobre el que deba versar el testimonio.

e) La referencia expresa a los derechos reconocidos en esta Ley al requerido.

2. La notificación habrá de hacerse con quince días de antelación respecto de la fecha en que haya de comparecer el requerido. Cuando se considere que concurren circunstancias de urgente necesidad, podrá hacerse en un plazo menor, que en ningún caso será inferior a tres días. 
Las principales características del requerimiento son las siguientes:

- En cuanto a quién corresponde efectuarlo, la Ley atribuye tal función al Presidente de la Cámara respectiva, así como también lo hace el Reglamento del Congreso respecto de su Presidente.

- Respecto al plazo para efectuar el requerimiento, tanto la Ley como el Reglamento del Congreso establecen un plazo de quince días de antelación, salvo que por circunstancias de urgente necesidad se haga con un plazo menor, que en ningún caso será inferior a tres días.

- Por lo que se refiere a los requisitos formales, la Ley dice que se formulará mediante citación fehaciente y en forma de oficio, mientras que el Reglamento del Congreso no dice nada al respecto.

- El contenido del requerimiento es objeto, asimismo, de regulación por la Ley 5/1984, la cual determina como necesaria la consignación de los siguientes datos:

3. El requerimiento a las personas jurídicas se entenderá dirigido a quienes ostenten su representación legal, los cuales podrán comparecer acompañados por aquellas personas que designe el órgano social de administración correspondiente.

4. Cuando el requerido reuniera la condición de funcionario público, se enviará copia de la citación a su superior jerárquico, a los solos efectos de su conocimiento".

El apartado 2 del artículo 52 del Reglamento del Congreso, establece que:

“a) La notificación del requerimiento para comparecer y de los extremos sobre los que se deba informar habrá de hacerse con quince días de antelación, salvo cuando, por concurrir circunstancias de urgente necesidad, se haga con un plazo menor, que en ningún caso será inferior a tres días.

b) En la notificación, el ciudadano requerido será advertido de sus derechos y obligaciones y podrá comparecer acompañado de la persona que designe para asistirlo.”

A título de ejemplo, el Reglamento de la Asamblea de Madrid, con mayor detalle, regula el requerimiento, señalando, en el artículo 75 que:

“3. Las Comisiones de Investigación elaborarán un plan de trabajo y requerirán, por conducto de la Presidencia, la comparecencia ante ellas de cualquier persona para ser oída.

4. Los requerimientos de comparecencia se efectuarán mediante citación fehaciente y en forma de oficio, en el que se hará constar:

a) La fecha del acuerdo y la Comisión de Investigación ante la que se ha de comparecer.

b) El nombre y apellidos del compareciente y las señas de su domicilio.

c) El lugar, el día y la hora de la comparecencia, con el apercibimiento de las responsabilidades en que se pudiera incurrir en caso de incomparecencia.

d) Los extremos sobre los que se debe informar.

e) La referencia expresa a los derechos reconocidos al compareciente.

La notificación habrá de hacerse con, al menos, tres días de antelación respecto de la fecha de la comparecencia.

Cuando el requerido reuniera la condición de funcionario público se enviará copia de la citación a su superior jerárquico, a los solos efectos de su conocimiento.

$\mathrm{Si}$, a juicio del Presidente, se pusieran de manifiesto por el requerido causas que justifiquen la incomparecencia, podrá efectuarse una ulterior citación en los mismos términos que la anterior.

El compareciente podrá actuar acompañado de la persona que designe para asistirle.

Los gastos que, como consecuencia del requerimiento, se deriven para el compareciente serán abonados, una vez debidamente justificados, con cargo al Presupuesto de la Asamblea." 
- La fecha del acuerdo en virtud del cual se requiere.

- La comisión de investigación ante la que se ha de comparecer.

- El nombre, apellidos y domicilio del requerido.

- El lugar, día y hora en que se ha de comparecer, con apercibimiento de las responsabilidades en que se pudiera incurrir en caso de desobediencia.

- El tema sobre el que deba versar el testimonio.

- La referencia expresa a los derechos que la Ley reconoce al requerido.

El Reglamento del Congreso, con menor detalle, sólo precisa que la notificación del requerimiento para comparecer y de los extremos sobre los que se deba informar, contendrá la advertencia de sus derechos y obligaciones.

En el supuesto de que por diferentes circunstancias de todo tipo -causas de fuerza mayor, enfermedad, etc.- fuera imposible la comparecencia, la Ley Orgánica establecía una ulterior citación en los mismos términos que la primera. Esta previsión, que estaba incluida en el mismo precepto que determinaba que la no comparecencia se consideraría un delito de desobediencia grave, ha quedado derogada ${ }^{59}$, probablemente por un error derivado de su ubicación sistemática. No obstante, parece que no quedaría más solución que la de aplicar el suprimido apartado y proceder a un nuevo requerimiento.

\subsubsection{El desarrollo de las intervenciones}

Una vez regulada la obligación de comparecer y los requisitos del requerimiento, la Ley Orgánica remite al procedimiento previsto en los respectivos Reglamentos de las Cámaras para el desarrollo de las comparecencias y a las normas que, en su caso, dicte el Presidente de la Cámara una vez oída la comisión. Esta última referencia posibilita la aprobación de normas de procedimiento especiales para cada comisión de investigación que se constituya en atención a sus circunstancias particulares.

No obstante esta remisión, no existe en los reglamentos, ni acuñado por los usos parlamentarios, un procedimiento específico, siendo las propias comisiones de investigación las que establecen los criterios con arreglo a los cuales se van a realizar.

Del estudio empírico, a través de los Diarios de Sesiones, del desarrollo de algunas comparecencias en determinadas comisiones de investigación del Congreso y de

59 La derogación del artículo 4 de la Ley Orgánica 5/1984, se llevó a cabo por la Ley Orgánica 10/1995, de 23 de noviembre, de reforma del Código Penal. 
la Asamblea de Madrid $^{60}$, se observa que los tiempos de duración de las intervenciones varían de unas comparecencias a otras, aunque de las intervenciones de los presidentes de las comisiones se desprende que ha sido la Junta de Portavoces la que, en reuniones preparatorias previas, ha acordado dichos tiempos.

Asimismo, se aprecia que las comparecencias comienzan con una intervención del compareciente en la que realiza una exposición general de la información que puede proporcionar a la comisión. El tiempo de esta intervención varía entre los diez y quince minutos, aunque también en alguna de ellas el compareciente actúa sin límite de tiempo.

A continuación, hay una primera intervención de los grupos parlamentarios, cuyo orden de actuación varía del Congreso a la Asamblea de Madrid. En el Congreso intervienen por orden de mayor a menor representación, cerrando siempre las intervenciones el grupo mayoritario, mientras que en la Asamblea de Madrid lo hacen de menor a mayor representación. El tiempo de duración de esta primera intervención tampoco tiene una regla fija, oscilando entre los diez y los veinte minutos.

El desarrollo de esta primera intervención presenta, a su vez, variantes. Así, hay comparecencias en las que se entabla un diálogo de preguntas-respuestas entre el representante del grupo y el compareciente. En otras, se produce una intervención consecutiva de cada grupo y el compareciente les contesta a todos ellos de una sola vez. Otra variante es que el compareciente interviene después de que lo haga cada grupo político, pero sin que llegue a establecerse un diálogo bajo la forma de preguntas-respuestas.

60 El análisis se ha realizado sobre las siguientes comisiones:

- Comisión de Investigación en el Congreso de los Diputados sobre el proceso de privatización de la empresa pública INTELHORCE. Compareciente: Sr. Ministro de Economía y Hacienda (Sr. Solbes Mira) en la sesión celebrada el 16 de noviembre de 1995.Diario de sesiones núm. 616. En línea: <http://www.congreso.es>.

- Comisión de Investigación en el Congreso de los Diputados para analizar la política desarrollada mediante ayudas comunitarias al cultivo del lino. Compareciente: Sr. Consejero de Agricultura y Comercio de la Junta de Extremadura (Sr. Álvarez Gómez) en la sesión celebrada el 22 de julio de 1999. Diario de Sesiones núm. 736. En línea: <http://www.congreso.es>.

- Comisión de Investigación en el Congreso de los Diputados sobre Gescartera. Compareciente: Sr. Gobernador del Banco de España y ex consejero de la Comisión Nacional del Mercado de Valores (Sr. Caruana Lacorte) en la sesión celebrada el 26 de octubre de 2001. Diario de Sesiones núm. 11. En línea: <http:// www.congreso.es>.

- Comisión de Investigación en el Congreso de los Diputados sobre el 11 de marzo de 2004. Compareciente: Sr. Comisario Jefe de los Tedax (Sr. Sánchez Manzano) en la sesión celebrada el 7 de julio de 2004. Diario de Sesiones del Congreso núm. 3, de 7 de julio de 2004. En línea: <http://www.congreso.es>.

- Comisión de Investigación en la Asamblea de Madrid al objeto de analizar y evaluar las responsabilidades que pudieran derivarse de actuaciones urbanísticas en el ámbito territorial de la Comunidad de Madrid. Compareciente: Sr. Romero de Tejada en la sesión celebrada el 5 de agosto de 2003. Diario de Sesiones núm. 22, de 5 de agosto de 2003. En línea: <http://www.asambleamadrid.es>.

- Comisión de Investigación en la Asamblea de Madrid sobre el presunto fraude en la venta de gasolinas. Comparecientes: El Presidente de la OCU (Sr. Sánchez Reyes) y el Portavoz de la OCU (Sr. Múgica) en la sesión celebrada el 2 de marzo de 1998. Diario de Sesiones núm. 576. En línea: <http://www.asambleamadrid.es>. 
Existe también un segundo turno de intervenciones en el que se reproduce el esquema de la primera intervención, cuya duración varía pero que, por regla general, es más breve que la primera. Para finalizar, quién cierra las intervenciones es siempre el compareciente.

\section{LÍMITES}

\section{Comisiones de investigación y poder judicial}

Uno de los temas más debatidos cuando se aborda el examen de las comisiones de investigación en nuestro derecho es el de su relación con los tribunales de justicia, ya que es indiscutible que del principio de la división de poderes y del estatus de independencia reconocido constitucionalmente al poder judicial se derivan unos límites importantes para las actividades de éstos órganos, lo que se manifiesta especialmente en aquellos casos en lo que hay un desarrollo paralelo de investigaciones parlamentarias y procesos judiciales ${ }^{61}$.

En el caso de que unos mismos hechos sean a la vez objeto de una comisión de investigación parlamentaria y de un procedimiento jurisdiccional, tanto los diferentes autores como la normativa de los países de nuestro entorno difieren, yendo desde la admisibilidad de la simultaneidad de ambos procesos a su estricta prohibición ${ }^{62}$.

Quienes defienden que se den las dos investigaciones al mismo tiempo argumentan que se trata de procesos que ejercen diferentes funciones y persiguen objetivos distintos, ya que mientras que el procedimiento penal se ocupa de los hechos en relación con la responsabilidad personal de un procesado, en el parlamentario se trata de aclarar objetivamente los hechos desde un punto de vista político ${ }^{63}$; por el contrario, los partidarios de la imposibilidad de las investigaciones simultaneas destacan los problemas que se plantean en el proceso de obtención de pruebas y testimonios, pues ambos órganos se deben servir de idénticos medios probatorios.

En nuestro derecho no hay ninguna norma que prohíba el que coincidan investigaciones parlamentarias y judiciales, por lo que se admite, no sin críticas, la compati-

61 Hay sistemas en los que este debate no existe, pues países como Italia o Alemania asimilan las actuaciones de las comisiones de investigación a las del poder judicial, y se ponen a su disposición los poderes establecidos en la normativa procesal para los tribunales de justicia. Frente a esta opción, otros sistemas como el nuestro, o los de Francia, Bélgica o los Países Bajos, se han decantado por una completa separación entre la actuación de esos órganos y la del poder judicial, de tal forma que las comisiones de investigación no disponen de los poderes de instrucción que contemplan las leyes procesales para los Tribunales de Justicia.

62 Por ejemplo, en Francia y en Reino Unido está establecida la incompatibilidad entre la investigación parlamentaria y el proceso judicial sobre un mismo asunto. Lo mismo ocurre en el Parlamento Europeo, donde las comisiones de este tipo no pueden ocuparse de asuntos que estén siendo tratados por un tribunal nacional o comunitario hasta que no termine el procedimiento judicial (artículo 138.c del Tratado de la Unión Europea).

63 Ignacio Torres Muro; Op. cit., en referencia a K.D. Friederich; p. 73. 
bilidad de ambas actuaciones, y así ha venido sucediendo en algunas de las comisiones de investigación constituidas en España.

No obstante esta posible simultaneidad, la reserva de la potestad jurisdiccional en exclusiva al poder judicial y la diferente naturaleza de los fines de las comisiones indagatorias obliga a determinar los principios sobre los que deben asentarse sus relaciones.

En primer lugar, el principio de no interferencia entre ambas instancias, que es básico para el correcto desarrollo de los dos procedimientos. Por más que el artículo 76.1 CE señale que las conclusiones de una comisión de investigación no son vinculantes para los Tribunales ni pueden afectar a las resoluciones judiciales, lo cierto es que, fundamentalmente a partir de la publicidad de sus sesiones sí que puede producirse una cierta interferencia, por lo que no está de más que la comisión adopte algunas cautelas tales como abstenerse de formular juicios sobre el modo en el que el juez ha conducido su propia investigación, ha examinado las pruebas documentales y ha interrogado a los testigos, en definitiva, sobre los criterios de valoración y la necesidad de los actos adoptados y, por supuesto, de formular juicios sobre la responsabilidad penal ${ }^{64}$.

El otro principio sobre el que deben asentarse las relaciones entre los órganos de encuesta y los jurisdiccionales es el principio de colaboración y auxilio. Este principio es de doble dirección, ya que se refiere tanto a la posibilidad que tiene la comisión de dirigirse al órgano judicial para obtener datos como que dicho órgano judicial pueda, a su vez, recibir información de la actuación llevada a cabo por la comisión.

En cuanto a que la comisión pueda recabar documentación del juzgado, no hay ningún precepto específico de obligada colaboración de los jueces y tribunales con las comisiones parlamentarias, por lo que habría que estar a lo que con carácter general establece el artículo 109 CE, que ya hemos comentado, en el entendimiento de que al referirse a cualquier autoridad del Estado en tal categoría quedarían comprendidos también los jueces y tribunales, aunque, como también hemos apuntado, en el caso de que la solicitud de documentación obrante en poder del juez o el tribunal fuera rechazada, la comisión no puede obligarles a que se la proporcione.

Un supuesto en el que el requerimiento de documentación ha sido más frecuentemente denegado por los Tribunales es cuando el proceso está sujeto al secreto sumarial. Ello es aceptable en la medida en que el secreto del sumario no crea una materia reservada pero protege las actuaciones jurisdiccionales de revelaciones indebidas. En este sentido, recordemos que el Reglamento del Congreso permite que las sesiones de la comisión no sean públicas en aquellos casos en los que a juicio de la comisión los asuntos a tratar coincidan con actuaciones judiciales que hayan sido declaradas secretas (artículo 64.4.b).

64 Marcos Francisco Massó Garrote. Op. cit., p. 144. 
Otra de las cuestiones sobre las que también se suscita cierto debate es el de la comparecencia ante una comisión de investigación de personas que ya han declarado ante un juez. La decisión de que se comparezca o no corresponde en exclusiva a la comisión, sin que el órgano jurisdiccional tenga la facultada de denegarla o autorizarla. Sin embargo, en la práctica, ha habido algún caso en que el juez no ha autorizado que una persona citada para comparecer abandone la cárcel para acudir a la sesión correspondiente.

En dirección contraria, el escenario que se plantea es el de si una autoridad judicial puede utilizar en su función jurisdiccional la información obtenida en el curso de una investigación parlamentaria. Cabe recordar aquí que el artículo 76 CE prevé que, aunque las conclusiones de estas comisiones no son vinculantes en sede judicial, ello no empece que el resultado de la investigación sea comunicado al Ministerio Fiscal para el ejercicio, cuando proceda, de las acciones oportunas. Junto a ello, la Ley Orgánica 5/1984, establece que si de las manifestaciones de un compareciente se dedujeran indicios racionales de criminalidad la comisión deberá ponerlo en conocimiento del Ministerio Fiscal, lo que, por otra parte, no es sino la concreción de la obligación de denunciar hechos posiblemente delictivos que corresponde a todos los ciudadanos y más a los poderes públicos.

Las anteriores consideraciones son aplicables a las comisiones de investigación municipales, pues no hay ninguna especialidad respecto de esto órganos sino que se refieren a principios generales de aplicación independientemente del ámbito en que se realizan las indagaciones.

\section{Salvaguarda de los derechos fundamentales}

La Ley Orgánica 5/1984, de 24 de mayo, de comparecencias ante las Comisiones de Investigación del Congreso y del Senado, en el artículo 1.2 establece que "Las Mesas de las Cámaras velarán por que ante las Comisiones de Investigación queden salvaguardados el respeto a la intimidad y el honor de las personas, el secreto profesional, la cláusula de conciencia y los demás derechos constitucionales"Quedan así enunciados como límites a los poderes de investigación de estos órganos parlamentarios los derechos al honor y a la intimidad personal y familiar, en cuanto implican la existencia de un ámbito propio y reservado frente a la acción y conocimiento de los demás, necesario para mantener una calidad mínima de la vida humana ${ }^{65}$. Se trata de unos derechos referidos a la vida privada de las personas, en las que nadie puede interferir sin estar debidamente autorizado ${ }^{66}$.

Según Torres Bonet, la Ley ha actuado acertadamente al explicitar la necesidad de tutelar estos derechos de forma individualizada respecto de los derechos consti-

65 STC 231/1988, de 2 de diciembre.

66 STC 137/1985, de 17 de octubre. 
tucionales en general, pues son los más fácilmente vulnerables por la actividad indagatoria de las comisiones de investigación ${ }^{67}$.

En cuanto al secreto profesional, se configura como un deber y un derecho del profesional a no declarar sobre su cliente y sobre las relaciones mantenidas con él. La función investigadora del Parlamento no podría llegar a exigir una respuesta relativa a esos datos a los profesionales requeridos a comparecer, pues, según la Ley Orgánica que regula la protección del derecho al honor, constituye una intromisión ilegítima la revelación de datos privados de una persona o familia conocidos a través de la actividad profesional u oficial de quienes los revela.

Como garantía para quienes sientan que sus derechos y libertades individuales no han sido suficientemente tutelados, como consecuencia de una investigación parlamentaria, cabe el recurso de amparo directo contra actos no legislativos de las Cámaras previsto en el artículo 42 de la Ley Orgánica del Tribunal Constitucional, aunque previamente a su interposición deberá acudirse a la Mesa de la Cámara en su función de garante de los derechos de los comparecientes.

Las anteriores reflexiones, si bien están referidas a la actividad de encuesta de las Cortes Generales, son perfectamente trasladables a la de un Ayuntamiento, pues la limitación a la que se refieren se desprende de todo el sistema jurídico constitucional sin que sea necesaria su manifestación expresa para un determinado ámbito territorial.

\section{DICTAMEN Y CONCLUSIONES}

Los trabajos de una comisión de investigación parlamentaria pueden finalizar por varias razones, a saber: que se produzca la disolución de la Cámara, en cuyo caso todas las comisiones cesan en sus mandatos; que se acuerde el final de las tareas investigadoras antes de llegar a su conclusión, o que se presente el resultado de las mismas.

Esta última es la forma más frecuente de poner término a su actividad, mediante la elaboración de un dictamen, denominado informe en el Senado, en el que se formaliza por escrito las conclusiones a las que se ha llegado tras el proceso de investigación ${ }^{68}$.

67 María Torres Bonet. Op. cit., p. 330.

68 El artículo 52 del Reglamento del Congreso, determina que:

“4. Las conclusiones de estas Comisiones, que no serán vinculantes para los Tribunales ni afectarán a las resoluciones judiciales, deberán plasmarse en un dictamen que será discutido en el Pleno de la Cámara. El Presidente del Congreso, oída la Junta de Portavoces, está facultado para ordenar el debate, conceder la palabra y fijar los tiempos de las intervenciones.

5. Las conclusiones aprobadas por el Pleno de la Cámara serán publicadas en el "Boletín Oficial de las Cortes Generales” y comunicadas al Gobierno, sin perjuicio de que la Mesa del Congreso dé traslado de las mismas al Ministerio Fiscal para el ejercicio, cuando proceda, de las acciones oportunas. 
El Reglamento del Congreso y, en términos similares la mayoría de lo reglamentos de las asambleas autonómicas prevén a este respecto que las conclusiones de las comisiones de investigación se plasmen en un dictamen que se discutirá en el Pleno de la Cámara. Asimismo, los reglamentos orgánicos de los Ayuntamientos que han regulado las comisiones de investigación incorporan, casi de manera unánime, el que las conclusiones se reflejen en un dictamen que se debatirá y votará en el Pleno municipal.

\section{Procedimiento de elaboración del dictamen}

En relación con el iter procedimental seguido para la elaboración del dictamen, el extremo más significativo reside en la ausencia de cualquier previsión al respecto en los reglamentos parlamentarios, lo cual ha planteado algunos problemas en la práctica que se han solventado, en general, acudiendo a las normas de procedimiento que puede dictar el Presidente, oída la comisión.

No obstante esta falta de regulación, en los dictámenes de las últimas comisiones de investigación del Congreso se puede comprobar que responden a un modelo estructurado a partir de tres grandes apartados que consisten en: un primero relativo a los antecedentes, a la creación y constitución de la Comisión; un segundo apartado en el cual se analizan los hechos objeto de la investigación, y un tercero dedicado a las conclusiones y las valoraciones.

Se aprecia, asimismo, que, si bien las conclusiones se elaboran a partir de la información recabada por la Comisión durante su investigación, no constituyen sólo una recopilación de esa información, sino que contienen un juicio valorativo sobre ella y se orientan a la determinación de la existencia de posibles responsabilidades políticas.

En relación con el objeto de la investigación se constata también que las conclusiones suelen tener dos tipos de pronunciamientos. En primer lugar, el mencionado juicio valorativo de los hechos investigados con eventual indicación de las responsabilidades políticas del Ejecutivo y, en segundo lugar, con mucha frecuencia, propuestas de actuación pro futuro con la incorporación de expresiones tales como: “... se

6. A petición del Grupo Parlamentario proponente se publicarán también en el "Boletín Oficial de las Cortes Generales" los votos particulares rechazados."

El artículo 60 del Reglamento del Senado, señala a este respecto que:

“3. Las conclusiones de estas Comisiones serán publicadas salvo que, en caso necesario, se acuerde lo contrario para la totalidad o parte de las mismas. No serán vinculantes para los Tribunales ni afectarán a las resoluciones judiciales.

4. El informe de las Comisiones de investigación podrá ser debatido en el Pleno con dos turnos a favor y dos en contra y la intervención de los Portavoces de los Grupos que lo soliciten. Ninguna de estas intervenciones excederá de quince minutos.

5. El resultado de las investigaciones será comunicado, en su caso, al Ministerio Fiscal para el ejercicio, cuando proceda, de las acciones que correspondan." 
recomienda al Gobierno..”; “La comisión insta...”; “La Comisión recomienda...”; “... sugiere instar al Gobierno..."; “parece recomendable...”, etc.

Estas propuestas de orientación política suelen consistir en sugerencias de regulación normativa de determinadas materias que, precisamente por la existencia de lagunas en su ordenación jurídica, han favorecido la aparición del conflicto investigado, aunque también pueden consistir en mandatos a la Administración. Esta segunda vertiente del contenido de las conclusiones de la encuesta se imbrica directamente con una clásica función parlamentaria cual es la de orientación o impulso político al Ejecutivo.

A la sesión de la comisión encargada del debate y aprobación del dictamen se deben llevar todas las conclusiones parciales que del estudio y conocimiento de la documentación aportada y comparecencias recibidas se hayan deducido. De acuerdo con el artículo 45 del Reglamento del Congreso y las normas sobre régimen de asesoramiento a las comisiones de Congreso de los Diputados y el Senado, el letrado adscrito a la comisión redactará y presentará los informes que recojan los acuerdos que aquella haya ido tomando.

Con toda la información recibida la comisión debatirá y votará cuantas propuestas de resolución se vayan planteando por los miembros. Las conclusiones finales de esa votación conformarán el dictamen de la comisión, que deberá redactar el letrado y que ha de recoger todos los acuerdos adoptados.

En el ámbito municipal la elaboración del dictamen con las conclusiones de la investigación, a salvo de disposiciones específicas al respecto, puede seguir un procedimiento similar al del ámbito parlamentario, pues, en definitiva, de lo que se trata es de confeccionar un documento que incluya un conjunto de resoluciones y recomendaciones, que una vez aprobadas se someterán a la deliberación y aprobación, en su caso, del Pleno del Ayuntamiento ${ }^{69}$.

69 Ejemplos de conclusiones de comisiones de investigación pueden encontrarse en las siguientes referencias:

- Texto aprobado por el Pleno del Congreso en relación con el dictamen de la Comisión de Investigación sobre la gestión de los fondos presupuestarios asignados a la Dirección General de la Guardia Civil, mientras fue Director General Don Luis Roldán, así como los votos particulares presentados al mismo. Resolución del Pleno del Congreso de los Diputados de 23 de junio de 1994. Boletín Oficial del Congreso, núm. 78, de 5 de julio de 1994, p. 1. En línea: <http://www.congreso.es>.

- Texto aprobado por el Pleno del Congreso de conformidad con el dictamen de la Comisión de Investigación sobre Gescartera y votos particulares mantenidos por los diferentes grupos parlamentarios que no se recogen en el citado texto. Resolución del Pleno del Congreso de los Diputados de 15 de noviembre de 2001. Boletín Oficial del Congreso, núm. 270, de 27 de noviembre de 2001, p. 19. En línea: <http:// www.congreso.es>.

- Texto aprobado por el Pleno del Congreso resultante del dictamen de la Comisión de Investigación del 11 de marzo de 2004 y votos particulares incorporados al mismo. Resolución del Pleno del Congre-

128 p. 2. En línea: <http://www.congreso.es>. 


\section{Debate y votación}

En las Cortes Generales, el dictamen aprobado por la comisión deberá ser trasladado al Pleno para su debate y posterior votación. El debate en el Pleno es obligatorio en el Congreso de los Diputados y potestativo en el Senado.

El procedimiento deberá desarrollarse siguiendo los criterios rectores de estos actos en general y con la observancia de dos principios: el de publicidad, incluyendo el de publicación de las distintas intervenciones en el Diario de Sesiones y de las conclusiones aprobadas por el Pleno en el Boletín Oficial de las Cámaras, y el de facultar a la Presidencia para ordenar el debate de las conclusiones -conceder la palabra y fijar los tiempos de las intervenciones conforme a los criterios que rigen las sesiones parlamentarias en general-. El Reglamento del Senado ha sido algo más preciso en este punto, adoptando unos criterios específicos consistentes en dos turnos a favor y dos en contra, y la intervención de los portavoces de los grupos que lo soliciten, no pudiendo exceder del plazo máximo de quince minutos las intervenciones de los oradores.

Una vez finalizado el debate se procede a la votación. Si se considera la redacción de los Reglamentos en sus justos términos - "Las conclusiones deberán plasmarse en un dictamen que será discutido en el Pleno de la Cámara” (Reglamento del Congreso); “El informe de las Comisiones de Investigación podrá ser debatido por el Pleno" (Reglamento del Senado)-, se comprueba como el objeto del debate es el dictamen, por lo tanto, la votación es de este documento y no sólo de las conclusiones contenidas en el mismo.

Debe subrayarse que las opiniones discrepantes, en todo o en parte, con el contenido del dictamen podrán manifestarse en votos particulares, a petición del grupo parlamentario proponente. El voto particular no posee por si mismo eficacia jurídica alguna, pues la decisión mayoritaria no deja de producir los efectos previstos por más opiniones disidentes que la acompañen. Desde el punto de vista jurídi-

- Dictamen aprobado por el Parlamento Vasco en relación con la Comisión de Investigación sobre las responsabilidades políticas surgidas de las irregularidades acontecidas en la provisión de la Oferta Pública de Empleo del Servicio Vasco de Salud-Osakidetza para el ejercicio 1990. Resolución del Pleno del Parlamento Vasco por la que se aprueba el Dictamen de la Comisión de Investigación, de 4 de julio de 1994. Boletín Oficial del Parlamento vasco núm. 141 Alea, de 22 de julio de 1994, p. 10571. En línea: <http://parlamento.euskadi.net>.

- Conclusiones relativas al dictamen de la Comisión de Investigación del Parlamento de Navarra sobre el denominado “Caso Otano". Resolución del Pleno del Parlamento de Navarra por la que se aprueban las conclusiones relativas al dictamen de la Comisión de Investigación. Boletín Oficial del Parlamento de Navarra núm. 75, de 12 de julio de 2005, p. 29. En línea: <http://www.parlamento-navarra.es>.

- Conclusiones de la Comisión de Investigación creada en el Ayuntamiento de Madrid por acuerdo del Pleno de 28 de noviembre de 2007 "caso guateque"). Acuerdo del Pleno del Ayuntamiento de Madrid por la que se aprueban las conclusiones relativas al dictamen de la Comisión de Investigación. Acuerdos de la sesión plenaria de 31 de marzo de de 2008. Apéndice 1 al punto 42 del orden del día de la citada sesión. En línea: <http://www.munimadrid.es>. 
co la única virtualidad de las voces discrepantes se deriva de su fuerza argumentativa. Los votos particulares referidos a las encuestas parlamentarias tiene una virtualidad esencialmente política, coadyuvando a la manifestación del principio democrático. La publicación del dictamen ya supone un conocimiento de lo acontecido en el seno de la Comisión y de las posturas de los diferentes grupos. Sin embargo la posibilidad de que éstos manifiesten su discrepancia respecto de la opinión mayoritaria permite, a través del cotejo de ambas versiones, proporciona una mayor aproximación a lo acontecido en la realidad. Respecto del contenido habitual de los votos particulares, el examen de los formulados a las conclusiones de las distintas comisiones de investigación evidencia la plasmación de discrepancias respecto de la mayoría en la opinión sobre el alcance e intensidad de la responsabilidad contraída por el Gobierno.

A falta de disposición expresa del reglamento debe entenderse que el dictamen será aprobado si así se pronuncia la mayoría simple de la Cámara pues éste es el procedimiento general de funcionamiento de estos órganos.

Por lo que se refiere a los Ayuntamientos, como ya se ha dicho, los reglamentos orgánicos que regulan las comisiones de investigación coinciden unánimemente en atribuir al Pleno municipal el debate y votación del dictamen que contiene las conclusiones de la actuación investigadora. En cuanto a la forma en que el dictamen deba ser incorporado al orden del día de la sesión plenaria, entendemos que, y siempre a salvo de lo que puedan disponer las propias normas orgánicas, en aplicación del ROF, cabría elevarlo al Pleno como un dictamen más, al que se acompañarían los votos particulares que, en su caso, se hubieran formulado (artículo 97.1).

En cuanto a la publicación, de no existir ninguna particularidad prevista vía reglamento, se seguirán las normas generales de publicación de los acuerdos plenarios.

\section{Efectos}

La eficacia jurídica de las conclusiones de los órganos de encuesta parlamentarios se produce ad intra de las Cámaras y se concreta en su posterior discusión en el Pleno. Sus efecto, por tanto, se limitan a poner de manifiesto unos hechos y a valorarlos políticamente. Ello resulta consecuente con la naturaleza de las actuaciones comentadas que, en cuanto actos de instrucción, son un documento de trabajo cuyo contenido no vincula siquiera la posterior decisión del Pleno de las Cámaras.

En cuanto a sus efecto ad extra, según el artículo 76 CE, y con similar contenido los reglamentos parlamentarios, las conclusiones de las comisiones de investigación "no serán vinculantes para los Tribunales, ni afectarán a las resoluciones judiciales, sin perjuicio de que el resultado de la investigación sea comunicado al Ministerio Fis-

130 cal para el ejercicio, cuando proceda, de las acciones oportunas". 


\section{EPÍLOGO}

Hasta aquí la teoría, cuestión distinta es la práctica o, mejor dicho, el resultado práctico de las comisiones de investigación, pues es evidente que el nivel de satisfacción con el resultado de las actuaciones de estos órganos se sitúa en la parte más baja de la tabla y las críticas son casi unánimes a la hora de valorarlas negativamente. Su instrumentalización para la lucha partidista las ha devaluado y su utilización mediática las ha convertido en un espectáculo no siempre edificante. $\mathrm{Si}$, además, nos encontramos con que en el caso de las comisiones de investigación municipales faltan elementos de cobertura legal para utilizar plenamente los medios de los que pueden servirse este tipo de órganos para desarrollar sus trabajos, la funcionalidad de su creación suele quedar limitada al interés que consiga despertarse en los medios de comunicación, caja de resonancia del quehacer político.

Nada mejor para ilustrar esta realidad que traer a colación las reflexiones de ese gran conocedor de lo que hoy en día acaece en el ámbito público que es el profesor Alejandro Nieto, quien, en su libro El desgobierno de lo público al referirse a las comisiones de investigación como uno de los contrapesos a la acción de gobierno, afirma que "Las comisiones de investigación (... ) de hecho nunca han funcionado entre nosotros por dos razones fundamentales: porque de ordinario corren paralelas a un proceso penal, al que se concede una primacía que permite ocultar datos bajo el pretexto del secreto sumarial; y porque el resultado final no depende tanto de la investigación realizada como de la opinión política de los miembros de la comisión. Con la consecuencia de que las conclusiones terminan siendo inexorablemente ambiguas por expresarse en distintas versiones, amparadas cada una de ellas por uno o varios grupos parlamentarios, aunque, como puede imaginarse, la que al final sale triunfante es la patrocinada por el Gobierno que para eso es el que domina la comisión". Mas demoledora aún es la opinión de Juan A. Santamaría Pastor, por él citado, para quien "la finalidad real de estas comisiones no es la supuesta averiguación de unos hechos, ni la formulación de propuestas que eviten en lo sucesivo la producción de hechos indeseables, sino otra muy distinta; son un mero pretexto para la creación de un escenario mediático, en el que lo importante es la liturgia escenográfica, frecuentemente escandalosa, que acompaña al principio y al fin de las sesiones, cuyo objetivo primordial es la difusión en la opinión pública de una hipótesis plausible de sospecha sobre la implicación del Gobierno, o de alguno de sus miembros, en actividades (habitualmente delictivas) que coopere en definitiva a la labor de su desgaste ante el electorado".

Así pues, ánimo a aquellos profesionales públicos a los que, desde sus puestos de responsabilidad técnica les corresponda prestar su asesoramiento en la creación de una comisión de investigación en su Ayuntamiento y el deseo de que este trabajo pueda serles de alguna utilidad en tal tarea. 


\section{REFERENCIAS BIBLIOGRÁFICAS}

Aguiló Lucia, L. (1995), El debate secreto en las comisiones de investigación y el derecho al honor, la intimidad y la propia imagen, en Parlamento y opinión pública. Madrid. Tecnos: Asociación Española de Letrados de Parlamentos, pp. 203-209.

Alonso de Antonio, J.A. (1990), “El deber de secreto de los parlamentarios”. Revista de la Facultad de Derecho de la Universidad Complutense, núm. 76, pp. 3-26.

Álvarez-Ossorio Fernández, C. (1995), Las comisiones de investigación: ¿actos de control o instrumentos de información parlamentaria? VI Jornadas de Derecho Parlamentario. Problemas actuales del control parlamentario. Madrid. Publicaciones del Congreso de los Diputados, pp. 805-814.

Aragón Reyes, M. (1986), "El control Parlamentario como Control Político"; Revista de Derecho Político de la UNED, núm. 23, pp.9-39.

Arévalo Gutiérrez, A. (1987), "Reflexiones sobre las comisiones de investigación o encuestas parlamentarias en el ordenamiento constitucional español”, Revista de las Cortes Generales, núm. 11, pp. 159-192.

Arévalo Gutiérrez, A. (1995), "Las Comisiones de investigación de las Cortes Generales y de las Asambleas legislativas de las Comunidades Autónomas"; Revista Española de Derecho Constitucional, núm. 43, pp.113-205.

Astarloa Huarte-Mendioca, I.; Cavero Gómez, M. (1998) “Cuestiones resueltas y cuestiones pendientes en el régimen jurídico de las comisiones de investigación”, Teoría y realidad constitucional. Núm. 1, pp. 123-181.

García Fernández, J. (2004), “Responsabilidad política y comisiones de investigación”, Temas para el Debate. Núm. 119, pp. 10-12.

García Mahamut, R. (2007), "Las comisiones de investigación y el poder judicial”. En Relaciones entre el poder legislativo y el poder judicial. Vitoria. Parlamento Vasco, pp.45-76.

García Mahamut, R. (1996). Las Comisiones parlamentarias de investigación en el Derecho Constitucional español. Madrid. McGraw-Hill.

García Morillo, J. (1985), El control Parlamentario del Gobierno en el ordenamiento español. Madrid. Publicaciones del Congreso de los Diputados.

García Morillo, J. (1995); El control parlamentario de las Cortes Generales y las Asambleas Legislativas de las Comunidades Autónomas: autonomía y comisiones de investigación. VI Jornadas de Derecho Parlamentario. Problemas actuales del control parlamentario. Madrid. Publicaciones del Congreso de los Diputados, pp.101-120.

García Morillo, J. (1996), “Principio de autonomía y control parlamentario: el supuesto de las comisiones de investigación", Revista Vasca de Administración Pública, num. 44 (I), pp. 143-169.

Gil-Robles y Gil-Delgado, J.M. (1995), “Las comisiones de investigación”. En España en la Europa comunitaria: balance de diez años. Madrid. Centro de Estudios Ramón Areces, pp.221-240.

Jiménez Díaz, A. (2000), “Comisiones de investigación, intimidad e información tributaria”, Revista Española de Derecho Constitucional. Núm. 60, pp. 45-88.

132 mación, control y responsabilidad. En la obra colectiva dirigida por S. Martín- 
Retortillo Baquer Estudios sobre la Constitución Española. Homenaje al Profesor Eduardo García de Enterría. Madrid. Cívitas. Vol. III: p.p 2003-2056).

Massó Garrote, M.F. (2001); Poderes y límites de la investigación parlamentaria en el Derecho Constitucional español. Madrid. Monografías del Congreso de los Diputados.

Medina Rubio, R. (1994), La función constitucional de las Comisiones parlamentarias de investigación. Madrid. Civitas.

Murillo de la Cueva, E.L. (1986), “Las Comisiones de investigación de las Cortes”; Revista de la Facultad de Derecho de la Universidad Complutense, núm. 10, pp.143173.

Navas Castillo, F. (2000), “Las Comisiones de Investigación y el Poder Judicial”, Revista del Poder Judicial. Núm. 60, pp.13-33.

Santaolalla López, F. (1982), El Parlamento y sus instrumentos de información: preguntas, interpelaciones y comisiones de investigación. Madrid. Editoriales de Derecho Reunidas.

Torres Bonet, M. (1998), Las comisiones de investigación, instrumento de control parlamentario del gobierno. Madrid. Publicaciones del Congreso de los Diputados.

Torres Muro, I. (1998), Las comisiones parlamentarias de investigación. Madrid. Cuadernos y debates del Centro de Estudios Políticos y Constitucionales.

Zúñiga Urbina, F. (1999), "Control parlamentario y comisiones investigadores", Revista de derecho político. Núm. 45, pp. 363-392. 
